\title{
AN OVERVIEW OF ASSISTIVE DEVICES FOR BLIND AND VISUALLY IMPAIRED PEOPLE
}

\author{
Menghan Hu, ${ }^{*, * *}$ Yuzhen Chen, ${ }^{*}$ Guangtao Zhai, ${ }^{* *}$ Zhongpai Gao, ${ }^{* *}$ and Lei Fan**
}

\begin{abstract}
Across the world, there are approximately 253 million people with vision impairments, and assistive devices have constantly been in demand. Advanced research has led to the development of numerous assistive devices for blind people and visually impaired people (VIP) to improve their quality of life. An overview of these different types of assistive devices such as canes, glasses, hats and gloves is presented in this survey. A FCBPSS (F: function, C: context, B: behaviour, P: principle, S: state, S: structure) architecture of visual impairment assistance system is preliminarily proposed to allow other researchers to design the assistive devices with the good experience and the high performance for blind people and VIPs in the future. As VIPs and blind people may have different behaviour patterns, a criterion for classifying different types of vision impairments is presented. Subsequently, we classify the substitutive senses for visual perception into five categories: vision enhancement, audition, somatosense, visual prosthesis, and olfactory and gustation. Two commonly used feedback forms, namely audition and vibration, are elaborated. Based on literature survey, we also present a summary prospective of the development of assistive devices: add more sensing and feedback modules, use the knowledge of perception mechanism and behaviour pattern as the design guideline and design more reliable validation experiments.
\end{abstract}

\section{Key Words}

Assistive device, perception, electronic mobility aids, vision impairments

\section{Introduction}

Statistics recently reported by the World Health Organization show that there are approximately 253 million people with vision impairments, among whom 36 million

* Shanghai Key Laboratory of Multidimensional Information Processing, East China Normal University, Shanghai 200241, PR China; e-mail: \{humenghan89, cyz1997724\}@163.com

** Institute of Image Communication and Information Processing, Shanghai Jiao Tong University, Shanghai 200240, PR China; e-mail: \{zhaiguangtao, gaozhongpai, lei.fan\}@sjtu.edu.cn Corresponding author: Guangtao Zhai

Recommended by Prof. Anmin Zhu

(DOI: 10.2316/J.2019.206-0302) are blind and 217 million have moderate-to-severe vision impairments [1]. The vision system is critical for humans to perceive the external world as more than $85 \%$ of external information can be obtained through the vision system. It largely influences our cognition and the progress of shaping spatial perception [2]. Due to its vast significance for every individual, the absence of vision will reduce individuals' proficiency in various skills [3], which in turn may lead to severe livelihood problems [4], [5]. Owing to the everincreasing blind and visually impaired population, assistive devices have constantly been in a huge demand for recent years [6]. For instance, as a traditional mobility aid, the white cane is the most popular among blind and visually impaired people (VIP) [7]. However, the performance is far from satisfactory as common white canes indicate limited information of obstacle position. For this reason, numerous state-of-the-art assistive devices have been developed, serving to gather more helpful clews of any obstacle, such as its category, volume and distance for VIPs and blind persons.

Research on assistive technology for VIP and blind people spans across different disciplines, including computer science, communications engineering, mathematics and mechanical engineering. Thanks to the advances in these disciplines in recent years, the development of assistive technology for VIP and blind people has also been promoted, with devices helpful to complete activities of daily living and even execute specific tasks such as print access [8]. Varied classifications of assistive devices exist. First, assistive devices can be divided into two categorizations, namely wearable and portable devices [9]. Wearable assistive devices allow completely hands-free interaction or minimize the use of hands when utilizing the device. In view of the fact that portable assistive devices usually require the users to get involved in the operation, most devices are designed to be more compact and lightweight. Moreover, assistive devices can be divided into three other categories, which are vision enhancement, vision replacement and vision substitution [6], [10]. For vision enhancement-based assistive techniques, they process visual signals from a camera and then display output signals on a screen. With the help of vision replacement-based assistive techniques, visual information is possible to be directly sent to the 


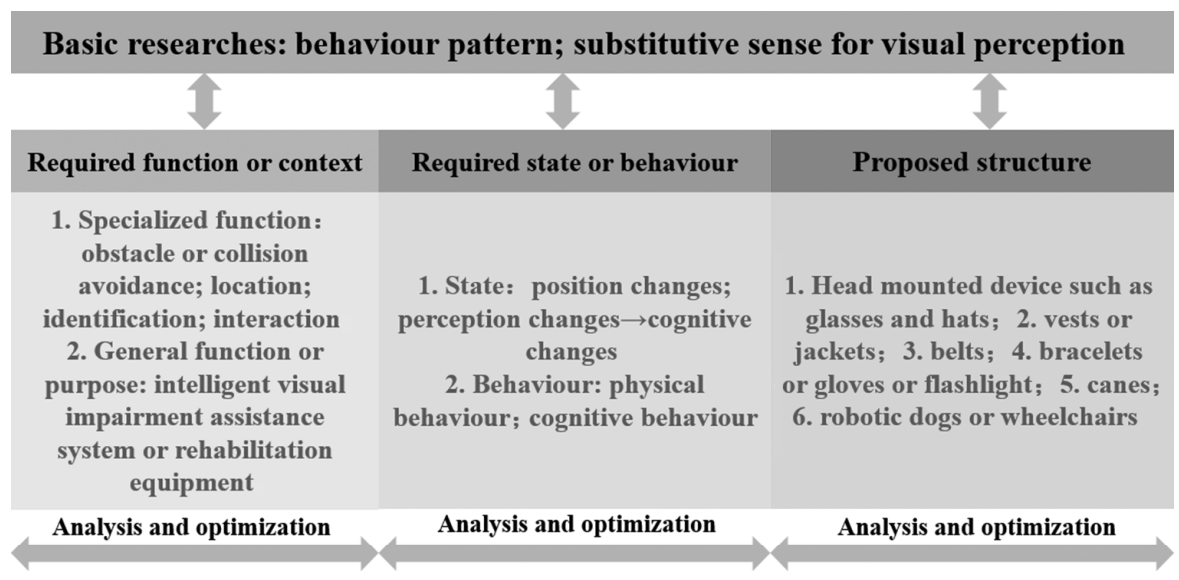

Figure 1. FCBPSS architecture of visual impairment assistance system.

human brain's visual cortex through implantable visual prosthesis [11]. Furthermore, vision substitution-based assistive devices, belonging to sensory substitution devices (SSDs), provide feasibility to leverage the obtained information from a variety of sensors and then give a feedback to the user via the nonvisual senses such as tactus and audition. The basic principle behind visual SSDs is that some other sensory modalities (e.g. audition) are used to provide environmental information normally by vision sense for VIPs and totally vision-deprived people [12]. From the view of image processing, the purpose of image processing for vision replacement and vision substitution is to convert the visual information into the spatially resolved electrical signals and nonvisual signals, respectively. Based on the feedback forms, we can conclude that the vision enhancement and vision replacement are, respectively, suitable for VIPs and blind people, while the vision substitution can be used for both VIPs and blind people. The assistive devices are always sorted into four groups based on the feedback types offered to end users. This classification does not emphasize the hardware and software architecture of assistive devices [13]. Therefore, in the current review, we classify the assistive devices based on the form of the final product or the technical construction of the device.

The remainder of this review is organized as follows. Section 3 introduces the classification of VIPs and blind persons. Section 4 lists the substitutive senses for visual perception. In Section 5, we elaborate assistive devices for VIPs and blind persons. The review is concluded in Section 6 .

\section{FCBPSS Framework of Visual Impairment Assistance System}

FCBPSS (F: function, C: context, B: behaviour, P: principle, S: state, S: structure) is a general framework for designing the systems [14], and it can serve as an excellent architecture to guide the design of visual impairment assistance system. Function, context, behaviour, state and structure refer to the role a system plays, the condition and environment under which a function is played by a system, the input (stimuli)-output (response) relationship and a set of components with their connection, respectively. Based on Zhang et al. [15], this framework can be applicable to any system including but not limited to the enterprise system and the engineering system. Some engineering problems have been solved on the basis of the FCBPSS framework [16]. Nonetheless, to the best of our knowledge, there is no framework for the development of visual impairment assistance system. For the purpose of allowing other researchers to design the better assistive devices for blind people and VIPs in the future, we preliminarily propose an FCBPSS architecture specific to the visual impairment assistance system according to the design concept described by Zhang et al. [14].

Figure 1 demonstrates the FCBPSS architecture of visual impairment assistance system. As shown in Fig. 1, the specialized functions of visual impairment assistance system contain the obstacle or collision avoidance, the location, the identification and the interaction. The general function or the purpose is to develop the intelligent visual impairment assistance system or rehabilitation equipment. The states include the changes in position, perception and cognitive (described in Section 4). Two behaviour types, namely the physical behaviour and the cognitive behaviour, have to be considered during the design process (described in Section 3). The proposed structure includes but is not limited to head-mounted devices such as glasses and hats, vests or jackets, belts, bracelets or gloves or flashlight, canes, robotic dogs or wheelchairs. This part has been reviewed in Section 5. It should be noted that the basic researches such as the studies on behaviour pattern and substitutive sense for visual perception are helpful for solving the engineering problems.

The design concepts of the current visual impairment assistance systems are relatively shallow, and we believe that the designed systems using the FCBPSS framework will have a very good experience and high performance. There is one review in the field of human-computer interaction, and the author of this review stated that the intelligent human-machine interactions can be divided into six levels and eight dimensions [17]. The visual impairment assistance system is also a kind of human-computer interaction equipment. Researchers in this field require to divide the systems to be established into several levels or dimensions according to the specific needs of the task and 


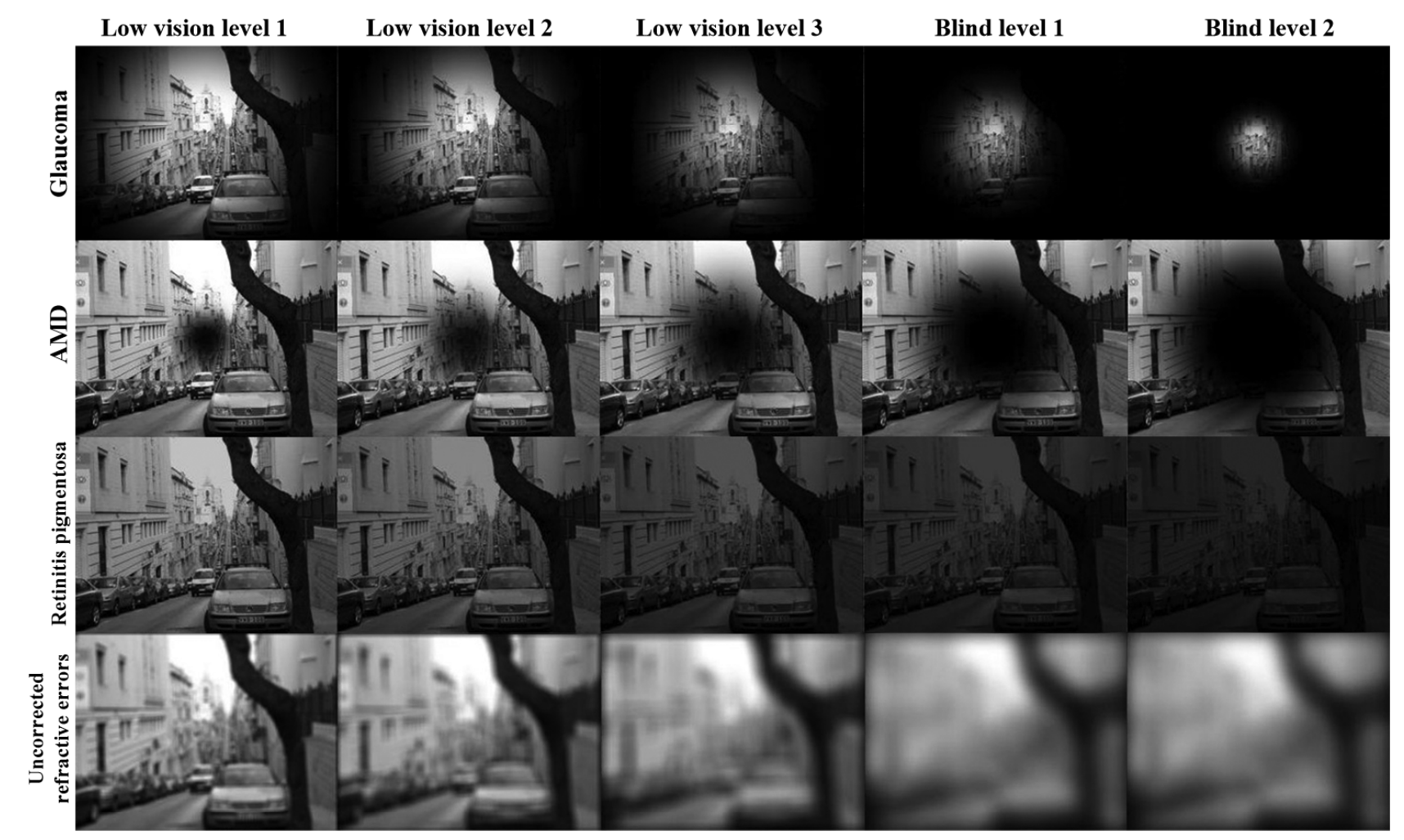

Figure 2. Classification of vision function based on the type of vision impairments (images are simulated by the custom-built software).

then design the appropriate FCBPSS framework to guide the development of the systems with good experience and high performance.

\section{Classification of VIPs and Blind People}

Why do we introduce the classification of VIPs and blind people for assistive devices at the beginning of this review? This arrangement is considered to be necessary for the reason that VIPs and blind people have different behaviour patterns due to the variations among individuals. Based on the literature evidence, the change of mentality caused by the altered sensory way of the outside world may have an impact on a person's behaviour pattern [18].

Some researchers have spent an adequate amount of time investigating the behaviour patterns of VIPs and blind people. Experimental results of a recent research conducted by Mihailovic et al. [19] showed that glaucoma severity was associated with several gait parameters, such as step length. Turano et al. [20] found that the gaze strategies of persons with normal vision and persons with retinitis pigmentosa $(\mathrm{RP})$ were significantly different. For example, walking persons with RP fixate over a larger area of the environment. In light of the experimental results, Aspinall et al. [21] reported that the fixation counts were significantly higher for persons with age-related macular degeneration (AMD) compared with normally sighted persons during navigation. The changes in the learning process reveal that VIPs and blind people exhibit different behaviour patterns at different stages. An important difference lies between those who are congenitally or early blind and those who are late blind, particularly in terms of sensory and cognitive abilities and preferences. A relevant review by Pasqualotto and Proulx [22] noted that the common classification of 'early' blind may be a misnomer as even a year or two of visual experience can lead to brain development akin to a late blind or indeed a sighted person. The late blind most often resembles the sighted in their sensory and cognitive profile. For congenital blindness, they indeed have superior auditory memory abilities [23].

The major global causes of vision impairments and blindness are uncorrected refractive errors, cataract, AMD and glaucoma. According to the International Classification of Diseases, the vision function is classified into four broad categories: normal vision, moderate vision impairments, severe vision impairments and blindness [1]. On the basis of overall visual ability, the grades of vision function consist of five levels by the WTO in 1973, which are low vision level 1, low vision level 2, low vision level 3, blind level 1 and blind level 2 .

The use of classification based on the type of vision impairments can provide a better guidance for the design and development of assistive devices. By counselling clinical ophthalmologists and examining literature, we summarize the categorization in line with the type of vision impairments as follows: (1) decrease in the sensitivity of the light, (2) blurred vision (caused by retinal anomaly or refractive error), (3) vision loss and (4) total blindness. One eye disease may lead to multiple kinds of vision impairments at the same time, so we generate the simulated images in the computer and summarize them in Fig. 2. As shown in the first line of Fig. 2, people with glaucoma in the early 
stage lose their peripheral visual field, and then a tubular vision slowly appears as the disease deteriorates. The second line of Fig. 2 demonstrates that visual impairment of AMD is mainly manifested as central vision loss. RP is an incurable eye disease, and the eyesight of persons with $\mathrm{RP}$ will get worse as the disease progresses (the third line of Fig. 2). Uncorrected refractive errors can be corrected by the use of a diopter lens (the last line of Fig. 2). The reason for the exclusion of cataract in Fig. 2 is that the cataract can be treated. These simulated images (Fig. 2) can provide the guidance for the design and development of assistive devices.

\section{Substitutive Sense for Visual Perception}

Vision impairments will alter the perception mechanism of VIP and blind people. Due to the total or partial absence of visual perception function, VIPs and blind people will be more dependent on other senses such as somatosense and audition.

Based on the literature survey, we summarize a tree diagram to demonstrate the existing substitutive senses for visual perception (Fig. 3). VIPs can see the outside world by means of the vision-enhancement techniques. One research group in the Harvard University focused on vision-enhancement techniques and used them to expand the visual field of VIPs [24], [25]. Hu et al. [26] attempted to develop a see-through glass associated with threshold-based enhancement algorithm to assist the people with night blindness. The visual prosthesis, one of the substitutive senses, directly displays the feedback information on the visual cortex in the human brain by the use of phosphene phenomenon [27], [28]. We will not discuss this feedback form as it involves some issues of medical researches, which is beyond the purpose of this survey. Readers can refer to the literature [29] for more information with respect to visual prosthesis. Thermal feedback, one of the somatosenses, can take advantage of temperature fluctuation on the human body surface to remind users of changes in the external environment. Lécuyer [30] designed a virtual reality system for VIPs to explore virtual environments. They used thermal feedback generated by 12 infrared lamps to simulate the virtual sun. Thermal feedback is highly influenced by ambient temperature, and, therefore, it is difficult to be perceived by users in some circumstances. Olfactory and gustation are two rare chemical feedback approaches, and they are seldom applied in assistive devices. VIPs and blind people mainly adopt the audition and tactus to take in information from the outside world and then process it to shape a right worldview that helps them understand life and make wise decisions. The majority of assistive devices use the audition and tactus among all feedback methods. In the following sections, we will emphatically review these feedback ways.

Spatial reference frames are of importance due to their relevance to navigation and mental mapping for VIPs and blind people [31]. We can refer to Hall's extra-personal space definition [32] to select the suitable substitutive sense for visual perception. Figure 4 illustrates the sensing ranges of these substitutive senses at different spatial scales [33].

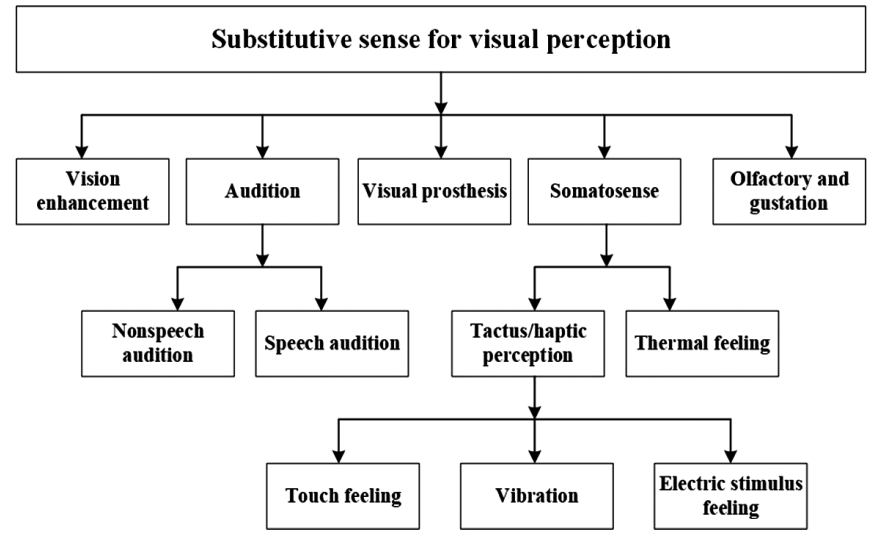

Figure 3. Tree diagram of substitutive sense for visual perception.

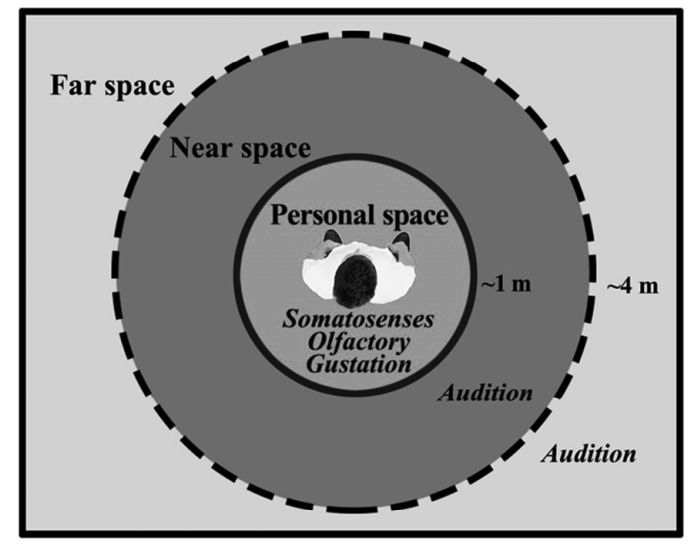

Figure 4. Hall's extra-personal space definition with minor revision for personal space.

Furthermore, Tversky [34] concluded more complex and efficient spatial thinking models. In one of her reports, she stated that there was a mental space except for the external space. Mental space is constructed from what we perceive, aided by what we think and infer, in the service of action in the world or imagined in the mind [35]. Spatial thinking in mental space can help VIPs and blind people create representations of a real-world space. More detailed work conducted by Pasqualotto et al. [36] showed differences between congenitally blind and late-blind people in their spatial reference frame preferences. Moreover, the same research group gave visual-like exposure to those who cannot see a room and thus provided allocentric reference frame information using auditory devices [37]. Hence, the understanding of mental space may be beneficial to the design of assistance devices.

\subsection{Audition}

The term audition is used to conclude all auditory perception means in assistive devices. This summative term may be incomprehensive, but it can be applied for reference by relevant researchers and interested readers. The sound processing speed of VIPs and blind people is faster than that of sighted people [38]. Moreover, auditory memory 
and retrieval abilities of congenitally blind people are superior to those of sighted people [39]. Survey results of the questionnaire showed that blind people of Iran are more inclined to use audio media rather than other media to access or utilize information [40]. Similar research was conducted by Kolarik et al. [41]. They found that VIPs outperformed sighted people in three cases: (1) when following the conversation switched from one person to another, (2) when locating the multiple speakers and (3) when separating the speech from music.

Findings of the previous literature evidence are in accordance with the perceptual enhancement hypothesis, that is VIPs and blind people will attempt to develop the ability of other senses to compensate for visual impairment [42], [43]. A recent survey concluded that complete blind people at an early stage show the superior performance in spatial hearing in the horizontal plane, but the performance in the vertical plane is unsatisfactory [44]. The spatial sound resolution ability of blind people is relatively low when they use the allocentric frame of reference. Besides, compared to early-onset blind individuals, late-onset blind people perform better in terms of spatial hearing. This indicates that the early visual experience is of great significance for the development of spatial hearing. Although VIPs and blind individuals exhibit better auditory processing ability, their brain region related to language processing is degraded [45]. This may be attributed to the fact that they seldom participate in social activities. The improvement of audio ability of VIPs and blind people is targeted, and it requires lengthy time to learn how to perceive the outside world using audition instead of vision.

In Fig. 3, we classify the auditory feedback into two categories viz. speech and nonspeech. The principle of speech feedback is to convert the ambient information into linguistic information [46], and subsequently, VIPs and blind people receive speech instructions via the earphone or speaker. Speech feedback is simple and intuitive, and the user can understand it without any learning process. Nevertheless, in some situations, speech feedback takes a longer time to describe the surrounding circumstances. There is no doubt that the user will feel annoyed and irritated [47]. Furthermore, delays in receiving information can even cause some irreversible accidents. The nonspeech feedback alerts the user using the music, environmental sounds or some artificial sounds [48]. In recent years, investigators have designed a variety of nonspeech cues such as spindex [49], spearcons [50] and audemes [51] to meet different application requirements. Although there is a learning process for nonspeech interface, this instruction can quickly convey information to users, which can address deficiencies of speech feedback. Researches carried out by Hussain et al. have validated the previous statement $[52]-[54]$.

\subsection{Tactus}

Tactus or haptic perception [55], one of the somatosenses, can be further separated into three parts, namely touch feeling, vibration and electric stimulus feeling (Fig. 3).
It is difficult to distinguish concepts of touch feeling and vibration. In our opinion, the touch feeling means the feeling given by the texture of an object in contact when we stroke or touch this object. The vibration means the feeling caused by external forces. Because the stimulation amount of touch feeling is less than that of vibration, few investigators have applied the touch feeling as feedback in assistive devices. Our research group used an electrical compass and a servo-driven pointer to develop an indoor localization system [56]. This system can give the direction information to the user with touch stimulation. In terms of electric stimulus feeling, it is arisen by electrical stimulation and can be used for a visual prosthesis. Like audition, tactus is also commonly used in a feedback interface for assistive devices.

Heller et al. [57] systematically investigated the haptic pattern perceived by blind individuals. They stated that the tactus is a crucial sense, which can be used to substitute for vision. Results of the experiments conducted by Occelli et al. [58] show that people with early-onset blindness reflect greater haptic sensitivity than the sighted. They also validated the hypothesis that people losing vision early can recognize objects by their haptic perception regardless of spatial transformations. Picard et al. [59] invited children, adolescents and young adults to compare their haptic memory capacities. The result demonstrated that the haptic memory ability is an age-related skill. Carpio et al. [60] found that there is no significant difference between blind and sighted school students in content acquisition or aesthetic appreciation of images. This indicates that the blind people can experience the world through their haptic perception and eventually reach the same cognitive level of sighted people. The research findings of Puspitawati et al. [61] showed that, compared to VIPs with slight visual impairment, the people with total blindness have the faster speed of processing haptic information. This may further illustrate that, for VIPs and blind people, dependence on tactile perception increases with the severity of visual impairment. Therefore, a feedback module of an assistive device can be designed to meet the needs of the people with varying degrees of visual impairment.

\section{Assistive Devices for Blind and Visually Impaired Persons}

Assistive technology, one of the information accessibility technologies, has attracted considerable attention worldwide owing to its remarkable social significance [4], [62]. Over the past decade, a variety of assistive devices have been developed for functional assistances of VIPs and blind people. We summarize these devices in the following sections. In Tables 1 and 2, although several assistance devices offer the same functionality, there exist differences in types of sensors used, feedback modes, hardware frameworks and data processing algorithms. Validation experiments are important for assistance devices, and, therefore, investigators design different experiments, aiming to verify their feasibilities and reliabilities of completing the specific task. 
Table 1

Summary of Assistive Canes for VIPs and Blind People about Sensors Used and Feedback Produced as well as Validation Methods

\begin{tabular}{|c|c|c|c|c|}
\hline Study & Sensor & Feedback & Functionality & Validation \\
\hline $\begin{array}{l}\text { Gupta et al. } \\
{[76]}\end{array}$ & $\begin{array}{l}\text { Ultrasonic sensor; } \\
\text { GPS receiver }\end{array}$ & Audition & Navigation & Tested in computer \\
\hline Fan et al. $[86]$ & $\begin{array}{l}\text { Ultrasonic sensor; } \\
\text { GPS receiver; } \\
\text { RGB-D camera }\end{array}$ & $\begin{array}{l}\text { Audition; } \\
\text { vibration }\end{array}$ & Navigation & $\begin{array}{l}\text { Tested in } \\
\text { outdoor open area }\end{array}$ \\
\hline $\begin{array}{l}\text { Silva and } \\
\text { Dias [90] }\end{array}$ & $\begin{array}{l}\text { Ultrasonic sensor; } \\
\text { inertia measurement } \\
\text { unit }\end{array}$ & Audition & Obstacle detection & $\begin{array}{l}\text { Tested by obstacles in } \\
\text { the path }\end{array}$ \\
\hline $\begin{array}{l}\text { Kumar et al. } \\
\text { [75] }\end{array}$ & Ultrasonic sensor & Audition & $\begin{array}{l}\text { Obstacle and potholes } \\
\text { detection }\end{array}$ & $\begin{array}{l}\text { Tested by } 10 \\
\text { volunteers }\end{array}$ \\
\hline $\begin{array}{l}\text { Majeed and } \\
\text { Baadel [73] }\end{array}$ & $\begin{array}{l}\text { RGB camera with } \\
270^{\circ} \text { lens }\end{array}$ & Audition & Facial recognition & Tested in database \\
\hline $\begin{array}{l}\text { Satpute } \text { et al. } \\
{[91]}\end{array}$ & $\begin{array}{l}\text { Ultrasonic sensor; } \\
\text { GPS receiver }\end{array}$ & $\begin{array}{l}\text { Audition; } \\
\text { vibration }\end{array}$ & $\begin{array}{l}\text { Navigation; obstacle } \\
\text { detection }\end{array}$ & None \\
\hline $\begin{array}{l}\text { Rizzo et al. } \\
{[92]}\end{array}$ & $\begin{array}{l}\text { Adaptive mobility } \\
\text { devices }\end{array}$ & Vibration & $\begin{array}{l}\text { Drop-off and obstacle } \\
\text { detection }\end{array}$ & Tested by 6 adults \\
\hline $\begin{array}{l}\text { Shah et al. } \\
{[77]}\end{array}$ & Ultrasonic sensor & Audition & $\begin{array}{l}\text { Navigation; obstacle } \\
\text { and potholes } \\
\text { detection }\end{array}$ & None \\
\hline $\begin{array}{l}\text { Sharma et al. } \\
{[78]}\end{array}$ & Ultrasonic sensor & $\begin{array}{l}\text { Audition; } \\
\text { vibration }\end{array}$ & $\begin{array}{l}\text { Static and dynamic } \\
\text { obstacles detection }\end{array}$ & $\begin{array}{l}\text { Tested in real-time } \\
\text { environment }\end{array}$ \\
\hline $\begin{array}{l}\text { Krishnan } \\
\text { et al. }[81]\end{array}$ & $\begin{array}{l}\text { Ultrasonic sensor; } \\
\text { GPS receiver; } \\
\text { RGB camera }\end{array}$ & Audition & $\begin{array}{l}\text { Navigation; obstacle } \\
\text { detection }\end{array}$ & Tested in database \\
\hline $\begin{array}{l}\text { Bolgiano and } \\
\text { Meeks [70] }\end{array}$ & Laser & $\begin{array}{l}\text { Audition; } \\
\text { vibration }\end{array}$ & Obstacle detection & None \\
\hline $\begin{array}{l}\text { Sugimoto } \\
\text { et al. }[93]\end{array}$ & $\begin{array}{l}\text { Ultrasonic sensor; } \\
\text { GPS receiver }\end{array}$ & Vibration & $\begin{array}{l}\text { Navigation; obstacle } \\
\text { detection }\end{array}$ & $\begin{array}{l}\text { Tested in preset } \\
\text { scenarios }\end{array}$ \\
\hline $\begin{array}{l}\text { Wankhade } \\
\text { et al. }[94]\end{array}$ & Infrared sensor & $\begin{array}{l}\text { Audition; } \\
\text { vibration }\end{array}$ & Obstacle detection & None \\
\hline $\begin{array}{l}\text { Kassim et al. } \\
{[88]}\end{array}$ & $\begin{array}{l}\text { RFID network; } \\
\text { digital compass }\end{array}$ & Audition & Indoor navigation & $\begin{array}{l}\text { Tested by the mobile } \\
\text { robot and human } \\
\text { subject }\end{array}$ \\
\hline Vera et al. $[71]$ & $\begin{array}{l}\text { RGB camera; laser } \\
\text { pointer }\end{array}$ & Vibration & Obstacle detection & $\begin{array}{l}\text { Tested by } 16 \text { sighted } \\
\text { persons }\end{array}$ \\
\hline $\begin{array}{l}\text { Alwis and } \\
\text { Samarawickrama } \\
{[95]}\end{array}$ & Ultrasonic sensor & $\begin{array}{l}\text { Audition; } \\
\text { vibration }\end{array}$ & Obstacle detection & None \\
\hline Pisa et al. $[89]$ & FMCW radar & None & Obstacle detection & $\begin{array}{l}\text { Tested by obstacle } \\
\text { with different } \\
\text { distances }\end{array}$ \\
\hline Buchs et al. [80] & Infrared sensors & $\begin{array}{l}\text { Audition; } \\
\text { vibration }\end{array}$ & $\begin{array}{l}\text { Waist-up obstacles } \\
\text { detection }\end{array}$ & $\begin{array}{l}\text { Tested by the trained } \\
\text { blind participants }\end{array}$ \\
\hline
\end{tabular}

(continued) 
Table 1

Continued

\begin{tabular}{|c|c|c|c|c|}
\hline Pinto et al. [96] & $\begin{array}{l}\text { Ultrasonic sensor; } \\
\text { GPS receiver }\end{array}$ & $\begin{array}{l}\text { Audition; } \\
\text { vibration }\end{array}$ & Obstacle detection & $\begin{array}{l}\text { Tested by obstacle } \\
\text { with different } \\
\text { distances }\end{array}$ \\
\hline Ye et al. $[74]$ & 3D camera & Audition & $\begin{array}{l}\text { Obstacle detection; } \\
\text { pose estimation }\end{array}$ & $\begin{array}{l}\text { Validated by data } \\
\text { from various indoor } \\
\text { scenes }\end{array}$ \\
\hline Dang et al. [72] & $\begin{array}{l}\text { Linear laser; } \\
\text { RGB camera; } \\
\text { inertial measure- } \\
\text { ment } \\
\text { unit }\end{array}$ & Audition & $\begin{array}{l}\text { Obstacle detection } \\
\text { and recognition }\end{array}$ & $\begin{array}{l}\text { Validated by the } \\
\text { obstacles with various } \\
\text { heights, types, } \\
\text { distances }\end{array}$ \\
\hline Niitsu et al. [82] & $\begin{array}{l}\text { Ultrasonic sensor; } \\
\text { infrared sensor; } \\
\text { compass; tri-axial } \\
\text { accelerometer }\end{array}$ & $\begin{array}{l}\text { Audition } \\
\text { (bone } \\
\text { conduction) }\end{array}$ & Obstacle detection & $\begin{array}{l}\text { Examined in } 20 \text { times } \\
\text { by } 1 \text { user }\end{array}$ \\
\hline $\begin{array}{l}\text { Takizawa et al. } \\
{[87]}\end{array}$ & Kinect sensor & Vibration & Object recognition & $\begin{array}{l}\text { Tested by } 2 \\
\text { blindfolded persons }\end{array}$ \\
\hline Jeong and Yu [97] & Ultrasonic sensor & Vibration & Obstacle detection & $\begin{array}{l}\text { Tested by } 4 \text { blind } \\
\text { folded and } 10 \text { blind } \\
\text { persons }\end{array}$ \\
\hline $\begin{array}{l}\text { Bay Advanced } \\
\text { Technologies Ltd. } \\
{[79]}\end{array}$ & Ultrasonic sensor & $\begin{array}{l}\text { Audition; } \\
\text { vibration }\end{array}$ & Obstacle detection & None \\
\hline Scherlen et al. [83] & $\begin{array}{l}\text { Infrared sensor; } \\
\text { brilliance; } \\
\text { water sensors }\end{array}$ & None & Object recognition & None \\
\hline Kim et al. [84] & $\begin{array}{l}\text { Ultrasonic sensor; } \\
\text { colour sensor; } \\
\text { Cds photo resistor }\end{array}$ & $\begin{array}{l}\text { Audition; } \\
\text { vibration }\end{array}$ & Obstacle detection & $\begin{array}{l}\text { Validate the usability } \\
\text { by } 7 \text { types of criteria }\end{array}$ \\
\hline $\begin{array}{l}\text { Shim and Yoon } \\
{[85]}\end{array}$ & $\begin{array}{l}\text { Ultrasonic sensor; } \\
\text { infrared sensor; } \\
\text { contact sensor } \\
\text { (two antennas) }\end{array}$ & Audition & Obstacle detection & None \\
\hline
\end{tabular}

Nearly all assistive devices listed later belong to SSDs. SSDs have been around for 40 years. The vibrotactile sensors were usually placed on the back to develop assistive device [63]. Subsequently, some investigators put an artificial sensor on the tongue [64]. The latter is the antecedent to the commercial BrainPort that is cited in Table 3. More recent, and highly promising, is the auditory device The vOICe [65]. It has been studied extensively for localization [66] and object identification [67]. There have been numerous neuroscience studies showing that The vOICe activates visual cortex in the blind as they perform tasks with images - suggesting that one can truly 'see' with the sound output of the device [68]. These devices in early stages have been widely validated in various tasks, settings and user groups. Thus the success and use are more easily ascertained than many devices cited in Tables 1 and 2 .

\subsection{Vision Substitution by Assistive Canes}

The use of assistive cane is critical in reducing the risk of collision, which can help VIPs and blind people to walk more confidently. Table 1 summarizes some assistive canes designed for VIPs and blind people.

In general, an assistive cane is developed by mounting sensing and feedback modules on a classic white cane. Subsequently, the assistive cane acquires information with respect to surroundings and transmits raw or (pre-)processed data to users via predefined feedback approach [69]. Bolgiano and Meeks [70] first put a laser into a cane to detect obstacles in the traveling path, and audio and vibratory signals were available when VIPs and blind people approach the obstacle.

Vera et al. [71] used an RGB camera and a laser pointer in combination to develop a virtual white cane for 
Table 2

Summary of Assistive Glasses for VIPs and Blind People about Sensors Used and Feedback Produced as well as Validation Methods

\begin{tabular}{|c|c|c|c|c|}
\hline Study & Sensor & Feedback & Functionality & Validation \\
\hline Sadi et al. $[98]$ & Ultrasonic sensor & Audition & Obstacle detection & Tested in lab conditions \\
\hline Kassim et al. [99] & Ultrasonic sensor & $\begin{array}{l}\text { Audition; } \\
\text { vibration }\end{array}$ & Obstacle detection & $\begin{array}{l}\text { Validated by blind spot } \\
\text { evaluation experiment }\end{array}$ \\
\hline Yi and Tian $[100]$ & RGB camera & Audition & $\begin{array}{l}\text { Text reading from } \\
\text { natural scene }\end{array}$ & Tested by 10 blind persons \\
\hline $\begin{array}{l}\text { Everding et al. } \\
{[102]}\end{array}$ & RGB camera & Audition & Obstacle detection & $\begin{array}{l}\text { Tested by } 2 \text { experiments } \\
(11 \text { and } 5 \text { persons, } \\
\text { respectively })\end{array}$ \\
\hline Wang et al. $[103]$ & RGB camera & Audition & $\begin{array}{l}\text { Navigation; way } \\
\text { finding }\end{array}$ & Evaluated in databases \\
\hline $\begin{array}{l}\text { Hassan and } \\
\text { Tang }[101]\end{array}$ & RGB camera & Audition & Text recognition & $\begin{array}{l}\text { Tested by several } \\
\text { sample texts }\end{array}$ \\
\hline $\begin{array}{l}\text { Pundlik et al. } \\
{[104]}\end{array}$ & Google Glass & Vision & $\begin{array}{l}\text { Smartphone screen } \\
\text { magnification }\end{array}$ & $\begin{array}{l}\text { Evaluated by } 8 \text { sighted and } \\
4 \text { visually impaired persons }\end{array}$ \\
\hline Neto et al. [105] & RGB-D camera & 3D audition & Face recognition & $\begin{array}{l}\text { Validated in databases and } \\
\text { by both blindfolded and } \\
\text { visually impaired users }\end{array}$ \\
\hline Stoll et al. $[106]$ & RGB-D camera & Audition & Indoor navigation & $\begin{array}{l}\text { Validated by } 2 \text { performance } \\
\text { metrics i.e. travel time } \\
\text { and error }\end{array}$ \\
\hline Hicks et al. [107] & RGB-D camera & Vision & $\begin{array}{l}\text { Scene recognition } \\
\text { and analysis }\end{array}$ & $\begin{array}{l}\text { Tested by } 4 \text { sighted and } \\
12 \text { visually impaired } \\
\text { participants }\end{array}$ \\
\hline Wu et al. $[108]$ & $\begin{array}{l}\text { Pico projector; } \\
\text { optical lenses }\end{array}$ & Vision & Vision enhancement & In simulated stage \\
\hline Lan et al. [112] & RGB camera & Audition & $\begin{array}{l}\text { Public sign } \\
\text { recognition }\end{array}$ & $\begin{array}{l}\text { Tested by some common } \\
\text { public signs }\end{array}$ \\
\hline Hu et al. $[26]$ & RGB camera & Vision & $\begin{array}{l}\text { Night vision } \\
\text { enhancement }\end{array}$ & $\begin{array}{l}\text { Evaluated on custom-built } \\
\text { databases }\end{array}$ \\
\hline
\end{tabular}

VIPs and blind people. In their device, the RGB camera in smartphone captures the laser beam reflection, and the distance from the cane to the obstacle is calculated using active triangulation. Through the personalized vibration generated by smartphone, the user will be warned if possible obstacles are located in traveling path. Furthermore, the magnitude of vibration is applied for the quantization of distance. Results of validated experiments demonstrated that the travel time of virtual white cane is less than that of the traditional white cane. The assistive cane equipped with the point laser may fail to detect the potholes and the obstacles in small and tiny size.

Dang et al. [72] proposed an assistive cane using a linear laser, an RGB camera and an inertial measurement unit as sensors to classify the type of obstacle and estimate the distance from the obstacle to the user. The inertial measurement unit is an electronic device that measures a user's angular rate to determine spatial coordinate frames.
The inertial sensor tracks the position of laser stripe in the navigation coordinate frame, and the subsequent analysis of the laser point coordinates in regard to the original laser stripe can divide obstacles into walls, stairs and blocks. The information gathered is transmitted to the user via a simple nonspeech feedback. The performance of this assistive cane is easily influenced by the strong illumination, thereby limiting the application scope of this assistive cane.

Due to the limited detecting or scanning range when using the laser as a sensor, we can only detect objects located in the region where the laser illuminates. To overcome this shortcoming, we need to leverage spatial information recorded by RGB camera. Majeed and Baadel [73] integrated an RGB camera with $270^{\circ}$ lens into an assistive cane, thus allowing us to capture much of environmental information. The proposed smart cane can help VIPs and blind people to dodge obstacles placed at the 
Table 3

Summary of Some Assistive Glasses Which Are Available on the Market

\begin{tabular}{|c|c|c|c|c|}
\hline Name & Company & $\begin{array}{l}\text { Launch } \\
\text { date }\end{array}$ & Functionality & Brief description \\
\hline $\begin{array}{l}\text { Google } \\
\text { Glass [113] }\end{array}$ & Google Inc. & 2012 & Direction recognition & $\begin{array}{l}\text { It is equipped with the RGB camera and } \\
\text { gyroscope and has all the functions of } \\
\text { mobile phone. As feedback, it can transmit the } \\
\text { information to the user via the bone-conduction } \\
\text { earphone and display screen. Google Glass is not } \\
\text { designed for visual assistance of the VIPs and } \\
\text { blind people, but we can do secondary } \\
\text { development based on it }\end{array}$ \\
\hline $\begin{array}{l}\text { eSight 3 } \\
{[114]}\end{array}$ & eSight Co. & 2017 & $\begin{array}{l}\text { No specific function } \\
\text { description }\end{array}$ & $\begin{array}{l}\text { It is mainly designed for the individuals who are } \\
\text { not completely blind. A high speed and quality } \\
\text { camera is loaded in this glass to capture what } \\
\text { the user is browsing. The obtained videos are } \\
\text { first subjected to image-enhancement processing } \\
\text { and then shown in two OLED screens. From the } \\
\text { display way, eSight } 3 \text { is something like the virtual } \\
\text { reality display device }\end{array}$ \\
\hline $\begin{array}{l}\text { OrCam } \\
{[115]}\end{array}$ & $\begin{array}{l}\text { OrCam } \\
\text { Technologies } \\
\text { Ltd. }\end{array}$ & 2015 & $\begin{array}{l}\text { Text reading; face } \\
\text { recognition; product and } \\
\text { money identification }\end{array}$ & $\begin{array}{l}\text { OrCam mainly consists of the RGB camera and } \\
\text { portable computer. It can be fixed on any eyeglass } \\
\text { frame and informs the user outside information } \\
\text { via the audio signals }\end{array}$ \\
\hline $\begin{array}{l}\text { Enchroma } \\
{[116]}\end{array}$ & $\begin{array}{l}\text { Enchroma, } \\
\text { Inc. }\end{array}$ & 2013 & $\begin{array}{l}\text { Colour contrast } \\
\text { enhancement }\end{array}$ & $\begin{array}{l}\text { Enchroma is designed for the colour blindness. } \\
\text { It does not leverage any digital processing } \\
\text { technology. Enchroma alters the original waves } \\
\text { using the specially designed lenses to help the } \\
\text { persons of colour vision deficiency see the } \\
\text { real colour }\end{array}$ \\
\hline Intoer [117] & $\begin{array}{l}\text { Hangzhou } \\
\text { KR-VISION } \\
\text { Technology } \\
\text { Co., Ltd. }\end{array}$ & 2017 & $\begin{array}{l}\text { Obstacle detection; } \\
\text { scene, money, puddle, } \\
\text { staircase, traffic signal and } \\
\text { zebra crossing recognition; } \\
\text { navigation }\end{array}$ & $\begin{array}{l}\text { It uses the infrared binocular camera to record } \\
\text { the environmental information illuminated by the } \\
\text { natural and structural light. It produces the } \\
\text { special encoded stereo to inform the user via } \\
\text { the bone-conduction earphone }\end{array}$ \\
\hline $\begin{array}{l}\text { BrainPort }^{\circledR} \\
\text { V100 }[118]\end{array}$ & Wicab, Inc. & 2015 & $\begin{array}{l}\text { Obstacle detection; } \\
\text { scene recognition }\end{array}$ & $\begin{array}{l}\text { BrainPort }{ }^{\circledR} \text { V100 is mainly composed of the RGB } \\
\text { camera mounted on a pair of glasses, hand-held } \\
\text { controller and tongue array containing } 400 \\
\text { electrodes. The outside information is converted } \\
\text { into electrical signals that are sent to the tongue } \\
\text { array on the tongue of the user. Before using this } \\
\text { device, there is a training phase }\end{array}$ \\
\hline
\end{tabular}

maximum distance of $10 \mathrm{~m}$, and moreover, it can be utilized to recognize different persons' faces.

Ye et al. [74] used a three-dimensional (3D) camera as a sensor to develop an assistive cane, aiming to estimating pose and recognizing obstacle. The type of $3 \mathrm{D}$ camera used in their study is SwissRanger SR4000, which is a small-sized $\left(65 \times 65 \times 68 \mathrm{~mm}^{3}\right)$ 3D time-of-flight camera. The speech feedback module serves as the communication media between human and cane. This assistive cane was validated by data collected from a variety of indoor scenes. Results demonstrated that the proposed cane could estimate pose and recognize objects with satisfactory performance. In their article, developers stated that they were working with orientation and mobility specialists as well as blind trainees of the World Service for the Blind in Arkansas to refine functions of their assistive cane.

Apart from the laser and RGB camera, the ultrasonic sensor is one of the widely used sensors in assistive device owing to its high-price/performance ratio. The ultrasonic sensor emits ultrasonic waves in the air, and then the reflected sound is received by the sensor. This sensor is always applied for detecting objects and measuring distance. Kumar et al. [75] developed an ultrasonic cane for aiding the blind people to navigate. This ultrasonic cane 
is equipped with three pairs of ultrasonic trans-receivers, thus enabling the blind people to know aerial and ground obstacles as well as potholes in front of them via audio warnings. The maximum working range of this ultrasonic cane is $1.5 \mathrm{~m}$, which is much less than that of the cane developed by Majeed and Baadel.

Gupta et al. [76] used an ultrasonic sensor and a GPS receiver together in classic canes. The addition of GPS module allows VIPs and blind people to travel outdoors using satellite network. Audio signals generated by Pygame module, a programming module to create games and animations, were used as the feedback to remind users. The range of distance measured by the attached ultrasonic sensor in cane is from 0.05 to $2 \mathrm{~m}$, which is slightly larger than that of the device developed by Kumar et al.

Several investigators reported that they used an ultrasonic sensor to establish assistive canes. Shah et al. [77] arranged four ultrasonic sensors in a stick. Among these ultrasonic sensors, three ultrasonic sensors are applied for obstacle detection and the remaining one for pothole detection. Their experimental results showed that maximum detection distances of the ultrasonic stick were $1.45,0.6$ and $0.82 \mathrm{~m}$ when the obstacles located on the front, leftfront and right-front, respectively. A similar smart stick was reported by Sharma et al. [78]. They stated that this smart stick was able to perceive obstacles of any height in front of or slightly sideways to users. Bay Advanced Technologies Ltd. [79] developed an ultrasonic sensor-based assistive cane named ' $\mathrm{K}$ ' Sonar, and this cane was available on the market.

Infrared sensor is also a very popular sensor selected by investigators for the development of the smart cane. It is an electronic sensor, which works by using a specific light sensor to detect a selected light wavelength in the infrared spectrum. This sensor can detect infrared light radiating from objects in its view field to detect object and measure distance. Buchs et al. [80] mounted two infrared sensors on a white cane. One infrared sensor was parallel to the horizontal plane while the other was approximately $42^{\circ}$ with respect to the horizontal plane. Such arrangement of infrared sensors allows this smart cane to detect waist-up obstacles. The detection range of this cane is only $1.5 \mathrm{~m}$. The addition of RGB camera can increase the detection range of developed smart cane. Krishnan et al. [81] applied an ultrasonic sensor and an RGB camera in the sensing mode of smart cane, and the testing result demonstrated that the maximum detection range was $3 \mathrm{~m}$.

Infrared sensor is usually used in conjunction with other types of sensors to form the multi-mode sensing array. Niitsu et al. [82] put four sensors viz. ultrasonic sensor, infrared sensor, compass and tri-axial accelerometer together on a classic cane. In this smart cane, a bone-conduction headphone was used for human-cane interaction in such a way that the feedback information could be passed to users unobtrusively. This assistive cane based on multi-mode sensing array can achieve the detection accuracy of $100 \%$ for wide obstacles, crossing and approaching persons, while $95 \%$ for thin obstacles. It should be noted that the bone conduction may have interference with several brain functions. Scherlen et al.
[83] leveraged an infrared sensor, a brilliance sensor and a water sensor in combination to develop a smart cane named 'RecognizeCane', which was capable of recognizing objects and their constituent materials. At present, four materials, namely metal (steel), glass, cardboard and plastic, can be successfully recognized. Also, the 'RecognizeCane' can distinguish the zebra crossing and water puddle using brilliance and water sensors, respectively. The brilliance sensor was also adopted by Kim et al. [84] in their smart cane to measure environmental brightness information. To detect obstacles in front accurately, two antennas used as the contact sensors, an ultrasonic sensor and an infrared sensor, were attached to a sensing unit of a smart cane by Shim and Yoon [85]. With the aid of contact sensors, this smart cane can effectively complement for ultrasonic and infrared sensors for detection of short-range obstacles.

Fan et al. [86], respectively, applied an RGB-D camera and an ultrasonic sensor to acquire dynamic visual environmental information and detect obstacles around. The RGB-D camera is able to obtain synchronized videos of both colour and depth. To implement outdoor navigation, they added a GPS module into the sensing unit. Results of validation experiments conducted in the open area demonstrated that the assistive cane installed in this sensing unit can help VIPs and blind people to travel outdoors safely. However, this cane cannot process the image data captured by RGB-D camera in real time. Takizawa et al. [87] also used an RGB-D camera in their sensing unit, and they called this developed cane as the Kinect cane. By the use of RGB-D camera, the Kinect cane can recognize different types of indoor obstacles, including chair, staircase and floor. Two blindfolded persons were invited to test the performance of proposed cane, and obtained results showed that the average search time by Kinect cane was significantly shorter than that by classic white cane.

Some other sensors are also used in sensing unit of assistive cane. Kassim et al. [88] mounted radio frequency identification (RFID) transponders on the floor and then installed an RFID reader at the end of cane. RFID is a technology that records the presence of an object using radio signals. When walking, the RFID reader reads RFID tags arranged on the floor in advance, and the addresses of these tags are sent for map processing. Subsequently, the auditory interface emits voice commands such as $90^{\circ}$ turn left after digital compass calibration. Results of small-sample experiment containing two human subjects showed that the RFID-based smart cane has a potential to help VIPs and blind people to walk independently in indoor environments. Frequency-modulated continuous wave (FMCW) radars and antennas were housed in a classic white cane by Pisa et al. [89] for obstacle detection. The result showed that this cane could receive reflections from a metallic panel up to $5 \mathrm{~m}$. FMCW radar is a short-range measuring radar set capable of determining the distance of object in its view field.

The assistive cane belongs to the portable assistive device. It is compact and lightweight, thus it is easily taken by users. Despite these advantages, the assistive cane needs to interact with users constantly. 


\subsection{Vision Substitution by Assistive Glasses}

Assistive glass is one of the wearable assistive devices. In Table 2, some assistive glasses designed for VIPs and blind people are presented. The assistive glass in general fixes sensing and feedback modules on a classic glass. Unlike the assistive cane, the assistive glass in general uses the visual signal as the feedback for users.

Sadi et al. [98] embedded an ultrasonic sensor in a traditional glass to develop a smart glass for walking assistance. The sensing region of attached ultrasonic sensor covers $3 \mathrm{~m}$ distance and $60^{\circ}$ angle. Processed information that corresponds to the distance of obstacle is sent to users via audio signals. Validation experiments carried out in the lab showed that detection accuracies of proposed glass were all beyond 93\%. Kassim et al. [99] compared the performance of three sensors inclusive of an ultrasonic sensor, an infrared sensor and a laser range by taking several metrics such as accuracy, size and weight into account. Finally, they selected ultrasonic sensors for the development of their assistive glass. As feedback, two warning modes viz. audition and vibration were designed in their device and users could switch the warning mode based on her or his preference or environment around. Kassim et al. gave an example: when a user comes to a noisy environment such as bus terminal or market, he or she can use the vibration mode instead of auditory mode, thus allowing the audio sense to hear ambient sounds. A blind spot evaluation experiment demonstrated the effectiveness of proposed smart glass.

Except for the ultrasonic sensor, the RGB camera is also commonly used in the sensing unit of assistive glass, and there are four publications that used RGB cameras to obtain outside information in Table 2. Yi and Tian [100] applied an RGB camera equipped on a glass for assisting VIPs to access text information in their daily lives. They reported that the further study should focus on improving the detection accuracy of scene text hidden in cluttered background. One possible solution for this is to explore more effective feature representations to establish more robust models, and subsequently, we write the obtained model into a processing unit of smart glass. A similar research was conducted by Hassan and Tang [101]. Their smart glass is only suitable for recognizing the text on hardcopy materials. Inspired by the principle of human visual perception, Everding et al. [102] deployed two RGB cameras on a classic glass to imitate two human retinas. The performance of their smart glass is satisfactory when subjects are static. For moving tests, the performance is still unknown. Wang et al. [103] embedded a saliency map algorithm into an RGB camera-based smart glass for the detection of indoor signs. Experimental results on their databases containing indoor signs and doors showed the usability of their glass. The output information of four abovementioned publications is all delivered to users using the audio form.

Pundlik et al. [104] did the secondary development for Google Glass to magnify the screen content of smartphone, thereby helping VIPs to easily access information displayed on the screen. They invited eight sighted and four VIP to employ calculator and music player apps on smartphone with the aid of proposed glass and built-in screen zoom app of phone. Comparison results showed that the assistive glass based on Google Glass outperformed the built-in screen zoom software in improving the ability of VIPs to read screen content.

As the RGB-D camera can acquire both colour and distance information, it has been widely used in assistive glass. Neto et al. [105] directly tied a Microsoft Kinect sensor to the user's head, and this assistive device informed the user outside information via 3D audio signal. This hardware architecture is somewhat abrupt. The similar hardware framework was adopted by Stoll et al. [106]. After validation experiments on 21 blindfolded young adults with 1-week interval, they deemed that this system was promising for indoor use, but still inefficient for outdoor scenarios. Hicks et al. [107] improved the hardware architecture and made it more like glass. They converted scene data obtained by RGB-D camera into a depth map that nearby objects were rendered into brighter. Subsequently, processed depth images were displayed on two OLED screens. With the validation experiment, for VIPs, the average detection distance was approximately $3 \mathrm{~m}$. Hence, further work needs to be done for increasing the detection distance of objects. The possible solution to this is to change the mechanical architecture of the glasses as the see-through display.

Wu et al. [108] designed a compact see-through neareye display system that could be used for the persons who are hyperopic. Unlike most assistive devices, this system does not use any digital processing technologies. The main principle of this system is that the light emitted by objects at a distance goes through preset aspherical surfaces, and the user can see the relatively clear image of object. According to their simulated results, the final image provided for users is nearly identical to the original image. However, the reduced brightness and distortion in image corners are also observed. This glass that can enhance vision ability of people with presbyopia is still in design phase.

$\mathrm{Hu}$ et al. [26] attempted to develop a see-through glass to assist the persons who suffer from the nyctalopia. They first analysed the vision model of night blindness and then derived the relationship between luminance levels and RGB grey scale of the image to develop the enhancement algorithm. Experimental results showed that the brightness of raw dark image could be significantly improved by the use of proposed algorithm. After the spatial distance and camera lens calibrations, the processed image is able to perfectly align with the view seen by users.

Apart from previous assistive glasses which are still at an engineering or concept stage, several assistive glasses have been available on the market. These commercialized glasses for visual assistance are summarized in Table 3. Google Glass is usually used for the secondary development, and many assistive glasses not listed in our survey are developed based on Google Glass [109], [110]. Targeting ends of eSight 3 are VIPs, and therefore, developers place two OLED display screens in front of user's eyes to play processed videos. Sensors of OrCam and Intoer 
Table 4

Summary of Some Assistive Devices with Various Forms

\begin{tabular}{|c|c|c|c|c|c|}
\hline Study & Modality & Sensor & Feedback & Functionality & Validation \\
\hline $\begin{array}{l}\text { Wang et al. } \\
{[119]}\end{array}$ & None & $\begin{array}{l}\text { RGB-D } \\
\text { camera }\end{array}$ & Audition & $\begin{array}{l}\text { Detection of stairs, } \\
\text { pedestrian crosswalks and } \\
\text { traffic signs }\end{array}$ & evaluated on databases \\
\hline $\begin{array}{l}\text { Satue and } \\
\text { Miah [120] }\end{array}$ & None & $\begin{array}{l}\text { Ultrasonic } \\
\text { sensor }\end{array}$ & $\begin{array}{l}\text { Nerve stimulation; } \\
\text { audition; vibration }\end{array}$ & Obstacle detection & $\begin{array}{l}\text { Tested in predefined } \\
\text { environments }\end{array}$ \\
\hline $\begin{array}{l}\text { Sekhar et al. } \\
{[121]}\end{array}$ & None & $\begin{array}{l}\text { Stereo } \\
\text { cameras }\end{array}$ & Audition & Obstacle detection & $\begin{array}{l}\text { Compared with the other } \\
\text { systems }\end{array}$ \\
\hline $\begin{array}{l}\text { Rao et al. } \\
{[122]}\end{array}$ & None & $\begin{array}{l}\text { Laser device; } \\
\text { RGB camera }\end{array}$ & None & $\begin{array}{l}\text { Pothole and uneven } \\
\text { surface detection }\end{array}$ & $\begin{array}{l}\text { Validated by the } \\
\text { performance metric }\end{array}$ \\
\hline $\begin{array}{l}\text { Gharani and } \\
\text { Karimi }[123]\end{array}$ & None & RGB camera & None & $\begin{array}{l}\text { Context-aware obstacle } \\
\text { detection }\end{array}$ & $\begin{array}{l}\text { Compared with the other } \\
\text { two algorithms using } \\
\text { different performance } \\
\text { metrics }\end{array}$ \\
\hline $\begin{array}{l}\text { Pattanshetti } \\
\text { et al. }[128]\end{array}$ & Hat & $\begin{array}{l}\text { Ultrasonic } \\
\text { sensor; } \\
\text { GPS receiver; } \\
\text { RGB camera }\end{array}$ & Audition; vibration & $\begin{array}{l}\text { Currency recognition; } \\
\text { obstacle detection; } \\
\text { Navigation }\end{array}$ & None \\
\hline Reshma [125] & Belt & \begin{tabular}{|l} 
Ultrasonic \\
sensor
\end{tabular} & Audition & Obstacle detection & $\begin{array}{l}\text { Tested by } 4 \text { blind } \\
\text { folded persons }\end{array}$ \\
\hline $\begin{array}{l}\text { Wattal et al. } \\
{[126]}\end{array}$ & Belt & $\begin{array}{l}\text { Ultrasonic } \\
\text { sensor }\end{array}$ & Audition & Obstacle detection & $\begin{array}{l}\text { Compared the measured } \\
\text { and actual distance and } \\
\text { position of obstacle }\end{array}$ \\
\hline $\begin{array}{l}\text { Mocanu et al. } \\
{[127]}\end{array}$ & Belt & $\begin{array}{l}\text { Ultrasonic } \\
\text { sensor; RGB } \\
\text { camera }\end{array}$ & Audition & $\begin{array}{l}\text { Obstacle detection and } \\
\text { recognition }\end{array}$ & $\begin{array}{l}\text { Tested by } 21 \text { visually } \\
\text { impaired subjects }\end{array}$ \\
\hline $\begin{array}{l}\text { Froneman } \\
\text { et al. }[138]\end{array}$ & Belt & $\begin{array}{l}\text { Ultrasonic } \\
\text { sensor }\end{array}$ & Vibration & Obstacle detection & $\begin{array}{l}\text { Evaluated by various } \\
\text { common static household } \\
\text { obstacles }\end{array}$ \\
\hline $\begin{array}{l}\text { Bhatlawande } \\
\text { et al. }[129]\end{array}$ & Bracelet & $\begin{array}{l}\text { Ultrasonic } \\
\text { sensor }\end{array}$ & Audition; vibration & $\begin{array}{l}\text { Way-finding; obstacle } \\
\text { detection }\end{array}$ & $\begin{array}{l}\text { Tested by } 2 \text { blindfolded } \\
\text { persons }\end{array}$ \\
\hline $\begin{array}{l}\text { Rangarajan } \\
\text { and Benslija } \\
{[130]}\end{array}$ & $\begin{array}{l}\text { Robotic } \\
\text { dog }\end{array}$ & $\begin{array}{l}\text { Force sensor; } \\
\text { RGB camera }\end{array}$ & Audition & $\begin{array}{l}\text { Obstacle detection; } \\
\text { word recognition }\end{array}$ & $\begin{array}{l}\text { Tested on flat ground } \\
\text { and slope }\end{array}$ \\
\hline $\begin{array}{l}\text { Lin et al. } \\
{[131]}\end{array}$ & Smartphone & RGB camera & Audition & $\begin{array}{l}\text { Obstacle detection and } \\
\text { recognition }\end{array}$ & $\begin{array}{l}\text { Tested by } 4 \text { visually } \\
\text { impaired persons }\end{array}$ \\
\hline $\begin{array}{l}\text { Lee et al. } \\
{[132]}\end{array}$ & Jacket & \begin{tabular}{|l} 
Ultrasonic \\
sensor; \\
GPS receiver; \\
RGB camera; \\
magnetic \\
compass \\
sensor \\
\end{tabular} & Audition; vibration & $\begin{array}{l}\text { Navigation; obstacle } \\
\text { detection }\end{array}$ & $\begin{array}{l}\text { Tested with various device } \\
\text { configurations in different } \\
\text { environments }\end{array}$ \\
\hline $\begin{array}{l}\text { Kim and } \\
\text { Song }[133] \\
\end{array}$ & Wheelchair & $\begin{array}{l}\text { Ultrasonic } \\
\text { sensor }\end{array}$ & None & Obstacle detection & $\begin{array}{l}\text { Tested at different moving } \\
\text { speeds }\end{array}$ \\
\hline $\begin{array}{l}\text { Altaha and } \\
\text { Rhee }[137]\end{array}$ & $\begin{array}{l}\text { Cane; } \\
\text { jacket; glove }\end{array}$ & $\begin{array}{l}\text { Ultrasonic } \\
\text { sensor }\end{array}$ & 3D audition & Obstacle detection & Tested by the blind person \\
\hline
\end{tabular}

(continued) 
Table 4

Continued

\begin{tabular}{|l|l|l|l|l|l|}
\hline $\begin{array}{l}\text { Mekhalfi } \\
\text { et al. }[\mathbf{1 3 9}]\end{array}$ & Jacket & $\begin{array}{l}\text { Laser sensor; } \\
\text { RGB camera }\end{array}$ & Audition & Indoor scene description & Tested in databases \\
\hline $\begin{array}{l}\text { Bhatlawande } \\
\text { et al. }[\mathbf{1 3 5}]\end{array}$ & $\begin{array}{l}\text { Bracelet; } \\
\text { Belt }\end{array}$ & $\begin{array}{l}\text { Ultrasonic } \\
\text { sensor; RGB } \\
\text { camera }\end{array}$ & Audition; vibration & Obstacle detection & $\begin{array}{l}\text { Tested by } 15 \text { trained blind } \\
\text { persons }\end{array}$ \\
\hline $\begin{array}{l}\text { Sivagami } \\
\text { et al. }[\mathbf{1 3 6}]\end{array}$ & Glasses; belt & $\begin{array}{l}\text { Ultrasonic } \\
\text { sensor }\end{array}$ & Audition & Obstacle detection & $\begin{array}{l}\text { Tested by the blindfolded } \\
\text { persons }\end{array}$ \\
\hline $\begin{array}{l}\text { Wu } \text { et } \text { al. } \\
{[\mathbf{1 4 0}]}\end{array}$ & $\begin{array}{l}\text { Wheeled } \\
\text { robots }\end{array}$ & $\begin{array}{l}\text { Ultrasonic } \\
\text { sensor; RGB } \\
\text { camera; } \\
\text { RFID reader }\end{array}$ & None & Indoor navigation & $\begin{array}{l}\text { Tested on the predefined } \\
\text { path }\end{array}$ \\
\hline $\begin{array}{l}\text { Spiers and } \\
\text { Dollar }[\mathbf{1 4 1}]\end{array}$ & $\begin{array}{l}\text { Hand-held } \\
\text { cube }\end{array}$ & $\begin{array}{l}\text { UWB } \\
\text { transmitter }\end{array}$ & $\begin{array}{l}\text { Shape-changing } \\
\text { tactus }\end{array}$ & Indoor navigation & $\begin{array}{l}\text { Tested by the sighted } \\
\text { persons }\end{array}$ \\
\hline $\begin{array}{l}\text { Fang } \text { et al. } \\
{[\mathbf{1 3 4}]}\end{array}$ & Flashlight & $\begin{array}{l}\text { RGB camera; } \\
\text { structured } \\
\text { light }\end{array}$ & Audition & Obstacle detection & $\begin{array}{l}\text { Evaluated on custom-built } \\
\text { databases }\end{array}$ \\
\hline
\end{tabular}

are an RGB camera and an infrared binocular camera, respectively. These two products both use the audio signal as feedback to inform users. Enchroma is designed for the assistance of colour blindness. Like the study conducted by $\mathrm{Wu}$ et al. [108], this product achieves its functionality (here is colour contrast enhancement) using a specially designed lens, instead of any digital processing technologies. The sensing unit of BrainPort ${ }^{\circledR} \mathrm{V} 100$ is similar to above-mentioned products, and the only difference is that it leverages the electric stimulus feeling as feedback. Developers of BrainPort ${ }^{\circledR}$ V100 consider that the tongue is extremely sensitive to electric stimulus, and hence, they place the tongue array which contains 400 electrodes in the user's tongue. This indicates that the resolution of BrainPort ${ }^{\circledR}$ V100 is $20 \times 20$ pixels. The intensity of stimulation represents the pixel intensity of the image obtained by RGB camera. In addition, due to the low resolution of tongue array, the background of the raw image requires to be eliminated [111].

\subsection{Vision Substitution by Other Forms of Assistive Devices}

Table 4 summarizes some assistive devices with various forms except for canes and glasses.

Several investigators only provide a core component of assistive device. By the use of an RGB-D image, Wang et al. [119] developed an imaging processing algorithmbased Hough transform for detection and recognition of stairs, pedestrian crosswalks and traffic signals. Results tested on their RGB-D databases showed the effectiveness of this system. Satue and Miah [120] applied an ultrasonic sensor to detect obstacles and then combined the electric stimulus, audition and vibration to warn the blind people of dangerous situations. As feedback, they placed the nerve stimulator unit on the wrist, and this unit would give an electric shock below the safe limit of human nerve stimulation according to the distance of obstacle. Sekhar et al. [121] used a real-time stereo vision algorithm written in FPGA to detect obstacles. A matching algorithm called zero-mean sun of absolute differences can maximize the hardware utilization, and therefore, their system is applicable to real-time applications. Rao et al. [122] combined a laser and an RGB camera in their assistive system to realize the pothole and uneven surface detection. From their study, we find that the laser can be served as the structural light for detecting various obstacles. Gharani and Karimi [123] calculated the optical flow between two consecutive RGB images and extracted feature points based on the texture of object and movement of the user. Experimental results showed that the combined use of optical flow and point track algorithms was capable of detecting both moving and stationary obstacles which were close to the RGB camera.

There existed the assistive devices in the other modalities:

Belt is a widely used modality for assistive device [124]. Reshma [125] furnished five ultrasonic sensors around the belt. This spatial arrangement of sensors allowed us to detect obstacles within the circle of $5 \mathrm{~m}$ in diameter. A similar assistive belt was reported by Wattal et al. [126] and the maximum detection distance was also $5 \mathrm{~m}$. Mocanu et al. [127] used one RGB camera and four ultrasonic sensors in their visual assistive belt. A total of 21 VIPs were involved in the evaluation experiment, and results demonstrated that the developed assistive belt could recognize both static and moving objects in highly dynamic urban scenes. Besides, each subject expressed a good experience.

Pattanshetti et al. [128] developed an assistive hat, which consisted of an ultrasonic sensor and an RGB camera for obstacle detection and currency identification, 
respectively. To achieve the outdoor navigation, they leveraged a GPS module in mobile phone.

Bhatlawande et al. [129] developed an ultrasonic bracelet for independent mobility of VIPs and blind people. With on-demand hand movements, this bracelet can warn the user of the obstacles in the range from 0.2 to $6 \mathrm{~m}$. Alerting signals were then sent to users via audition and vibration.

Rangarajan and Benslija [130] reported a voice recognition robotic dog that could guide VIPs and blind people to the destination avoiding obstacles and traffic. This robotic dog had been successfully tested on the flat ground and slope. Lin et al. [131] directly used a built-in RGB camera of smartphone to detect and recognize obstacles. However, the recognition accuracy of obstacle in their study was only $60 \%$. In the real world, this is insufficient for VIPs and blind people to avoid obstacles around them.

Lee et al. [132] put an ultrasonic sensor array, a GPS receiver, an RGB camera and a magnetic compass sensor on the jacket to help VIPs and blind people to travel outdoors. This assistive jacket had been tested with various device configurations in different environments, and results demonstrated that the sensor and receiver network had a potential ability to guarantee the safe outdoor navigation.

Kim and Song [133] extended the functionality of a classic wheelchair by adding multiple ultrasonic sensors, and the wheelchair can therefore execute efficient obstacle searching. The excellent performance had been observed when the updated wheelchair was tested at different moving speeds.

An assistive flashlight was designed by Fang et al., who used an RGB camera and a structured light generated by a laser array to detect obstacles [134]. The laser of high refresh rate was used to achieve a visual bifurcation effect so that people around could not perceive the laser light but the camera could capture it. Therefore, the flashlight can operate in an unobtrusive pattern.

To further improve the performance of assistive device, some investigators simultaneously used several modalities of assistive devices to reach the specific assistive purposes. Bhatlawande et al. [135] installed an RGB camera and an ultrasonic sensor on a belt and a bracelet, respectively, for assisting the blind people in walking. Based on results of evaluation experiment with 15 blind people, the dual-mode assistive device exhibited excellent performance: $93.33 \%$ participants expressed satisfaction, $86.66 \%$ comprehended its operational convenience and $80 \%$ appreciated the comfort of the system. Sivagami et al. [136] also developed dual-mode assistive devices containing two modalities viz. glasses and a belt for VIPs and blind people to travel under unknown circumstances. Altaha and Rhee [137] proposed three different modalities viz. jacket, glove and cane for obstacle detection. They arranged three ultrasonic sensors on the front, left and right sides, respectively, thus allowing us not only to detect the presence of nearby objects but also to measure the distance of objects from users. We suggest that they can in future use these three assistive devices in combination to increase the detection range and distance.

\section{Conclusion and Prospective}

Although numerous assistive devices are available, they are not yet effectively adopted by VIPs and blind people. One reason is that these assistive devices can only act in a restricted spatial range due to their limited sensors and feedback modes. The other reason is that the performance of these assistive devices is not effectively validated. As shown in the aforementioned tables, in many cases, only blindfolded sighted subjects were invited to validation experiments. Actually, cognitive strategies observed in VIPs and blind people are significantly different from those in blindfolded sighted subjects.

In this section, we will next discuss three prospectives for assistive devices to conclude this survey: (1) increase the diversity of input and output information to guarantee the reliability of assistive device, (2) develop the assistive device based on perception mechanism and behaviour pattern of VIPs and blind people and (3) design more reliable experiments to validate the feasibility of assistive device.

The diversity of feedback can increase the reliability of final assistive devices. The multimodal feedback, including audition, thermal and vibration was embedded into the virtual reality system, which allows VIPs and blind people to explore and navigate inside virtual environments [30]. Simultaneously, the use of sensor fusion framework for assistive device allows us to obtain more important information about the surrounding environment. Rizzo et al. [142] found that the depth information extracted from a stereoscopic camera system could ignore specific potential collision hazards, and the addition of infrared sensors could offer a reliable distance measurement to remove this inconsistency of depth inferred from stereo images. Hence, for the specific task, if used sensors give inconsistent measurements, the alternate sensing modality can be chosen to remedy this inconsistency.

Study of changes in the connectivity of the functional areas of the human brain can help us understand the change in perception mechanism of VIPs and blind people [143]. Because congenitally blind people rely more on audition or tactus information, the connectivity of multisensory brain areas of them will be more complicated [144]. Therefore, the introduction of brain imaging is essential for the design of assistive devices. Luckily, there are some reviews available in a recent special issue of 'Neuroscience and Biobehavioral Reviews' that cover the spectrum of SSDs and their relevance for understanding the human brain (http://www.sciencedirect.com/science/journal/01497634/ 41). In addition, we can develop better assistive devices according to the idea of bionics [145].

Currently, the performance of assistive devices is rarely or inadequately validated by VIPs and blind individuals. As cognitive strategies of VIPs and sighted people are significantly different, it is not guaranteed that the performance validated by sighted blindfolded people represents that by VIPs and blind people [69]. Therefore, it is very necessary to invite numerous VIPs and blind people from different blind associations to test the performance of developed assistive device. Furthermore, real-world 
scenarios are far more complicated, and testing environments should fully cover any possible application scenario.

\section{Acknowledgement}

This work was sponsored by the Shanghai Sailing Program (No. 19YF1414100), the National Natural Science Foundation of China (No. 61831015, No. 61901172), the STCSM (No. 18DZ2270700), and the China Postdoctoral Science Foundation funded project (No. 2016M600315). The authors would also like to acknowledge Ms. Huijing Huang, Ms. Shuping Li, and Mr. Joel Disu for providing assistance with the English language revision.

\section{References}

[1] World Health Organization, Visual impairment and blindness (2017). Available from: http://www.who.int/mediacentre/ factsheets/fs282/en/.

[2] M. Gori, G. Cappagli, A. Tonelli, G. Baud-Bovy, and S. Finocchietti, Devices for visually impaired people: High technological devices with low user acceptance and no adaptability for children, Neuroscience \& 6 Biobehavioral Reviews, 69(Supplement C), 2016, 79-88.

[3] T. Nakamura, Quantitative analysis of gait in the visually impaired, Disability \& Rehabilitation, 19(5), 1997, 194-197.

[4] A. Bhowmick and S.M. Hazarika, An insight into assistive technology for the visually impaired and blind people: stateof-the-art and future trends, Journal on Multimodal User Interfaces, 11(2), 2017, 149-172.

[5] M.C. Domingo, An overview of the Internet of Things for people with disabilities, Journal of Network and Computer Applications, 35(2), 2012, 584-596.

[6] D. Dakopoulos and N.G. Bourbakis, Wearable obstacle avoidance electronic travel aids for blind: A survey, IEEE Transactions on Systems Man \& Cybernetics Part C, 40(1), 2009, $25-35$.

[7] J.M. Batterman, V.F.Martin, D. Yeung, and B.N. Walker, Connected cane: Tactile button input for controlling gestures of iOS voiceover embedded in a white cane, Assistive Technology, 30(2), 2018, 91-99.

[8] J.R. Terven, J. Salas, and B. Raducanu, New opportunities for computer vision-based assistive technology systems for the visually impaired, Computer, 47(4), 2014, 52-58.

[9] R. Velázquez, Wearable assistive devices for the blind, Lecture Notes in Electrical Engineering, 75, 2016, 331-349.

[10] W. Elmannai and K. Elleithy, Sensor-based assistive devices for visually-impaired people: current status, challenges, and future directions, Sensors, 17(3), 2017, 565.

[11] P.M. Lewis, L.N. Ayton, R.H. Guymer, et al., Advances in implantable bionic devices for blindness: A review, $A N Z$ Journal of Surgery, 86(9), 2016, 654-659.

[12] L. Renier and A.G.D. Volder, Sensory substitution devices (New York, USA: Oxford Handbooks, 2013).

[13] G. Motta, T. Ma, K. Liu, et al., Overview of smart white canes: connected smart cane from front end to back end, in R. Velazquez (ed.), Mobility of visually impaired people (Cham: Springer, 2018), 469-535.

[14] W. Zhang, Y. Lin, and N. Sinha, On the function-behaviorstructure model for design, Proceedings of the Canadian Engineering Education Association, 2005, 1-8.

[15] W. Zhang and J. Wang, Design theory and methodology for enterprise systems, Enterprise Information Systems, 10, 2016, 245-248.

[16] Z.M. Zhang, Q. An, J.W. Li, and W.J. Zhang, Piezoelectric friction-inertia actuator-A critical review and future perspective, The International Journal of Advanced Manufacturing Technology, 62(5-8), 2012, 669-685.

[17] Y. Lin, Towards Intelligent Human-Machine Interactions: Human Assistance Systems (HAS), ASME Magazine Special Issue on Human-Machine Interactions, 2017, 139(06), 4-8.
[18] D.I. Anderson, J.J. Campos, D.C. Witherington, et al., The role of locomotion in psychological development, Frontiers in Psychology, 4(2), 2013, 1-7.

[19] A. Mihailovic, B.K. Swenor, D.S. Friedman, S.K. West, L.N. Gitlin, and P.Y. Ramulu, Gait implications of visual field damage from glaucoma, Translational Vision Science \& Technology, 6(3), 2017, 23.

[20] K.A. Turano, D.R. Geruschat, F.H. Baker, J.W. Stahl, and M.D. Shapiro, Direction of gaze while walking a simple route: persons with normal vision and persons with retinitis pigmentosa, Optometry \& Vision Science, 78(9), 2001, $667-675$

[21] P.A. Aspinall, S. Borooah, C. Al Alouch, et al., Gaze and pupil changes during navigation in age-related macular degeneration, British Journal of Ophthalmology, 98(10), 2014, 1393-1397.

[22] A. Pasqualotto and M.J. Proulx, The role of visual experience for the neural basis of spatial cognition, Neuroscience \&6 Biobehavioral Reviews, 36(4), 2012, 1179-1187.

[23] A. Pasqualotto, J.S.Y. Lam, and M.J. Proulx, Congenital blindness improves semantic and episodic memory, $B e-$ havioural Brain Research, 244(Supplement C), 2013, 162-165.

[24] E. Peli and J.-H. Jung, Multiplexing prisms for field expansion, Optometry and Vision Science, 94(8), 2017, 817-829.

[25] A.D. Hwang and E. Peli, An augmented-reality edge enhancement application for Google Glass, Optometry and Vision Science: Official Publication of the American Academy of Optometry, 91(8), 2014, 1021-1030.

[26] C. Hu, G. Zhai, and D. Li. An Augmented-Reality night vision enhancement application for see-through glasses, IEEE International Conference on Multimedia \& Expo Workshops, 2015.

[27] E.M. Schmidt, M.J. Bak, F.T. Hambrecht, C.V. Kufta, D.K. O'rourke, and P. Vallabhanath, Feasibility of a visual prosthesis for the blind based on intracortical micro stimulation of the visual cortex, Brain, 119(2), 1996, 507-522

[28] I. Bókkon, Phosphene phenomenon: A new concept, Biosystems, 92(2), 2008, 168-174.

[29] P.M. Lewis, H.M. Ackland, A.J. Lowery, and J.V. Rosenfeld, Restoration of vision in blind individuals using bionic devices: A review with a focus on cortical visual prostheses, Brain Research, 1595, 2015, 51-73.

[30] A. Lécuyer, P. Mobuchon, C. Mégard, J. Perret, C. Andriot, and J.-P. Colinot, HOMERE: A multimodal system for visually impaired people to explore virtual environments, IEEE Virtual Reality, 2003, 251-258.

[31] S. Wong, Traveling with blindness: a qualitative space-time approach to understanding visual impairment and urban mobility, Health \& Place, 49, 2018, 85-92.

[32] E.T. Hall, The hidden dimension, Hidden Dimension, 6(1), 1966, 94.

[33] P. Strumillo, Electronic interfaces aiding the visually impaired in environmental access, mobility and navigation, IEEE 3rd International Conference on Human System Interaction, 2010, 17-24.

[34] B. Tversky, Spatial Intelligence: Why It Matters from Birth Through the Lifespan (New York, USA: Routledge, 2017).

[35] B. Tversky, On abstraction and ambiguity, in J.S. Gero (ed.), Studying visual and spatial reasoning for design creativity (Dordrecht: Springer Netherlands, 2015), 215-223.

[36] A. Pasqualotto, M.J. Spiller, A.S. Jansari, and M.J. Proulx, Visual experience facilitates allocentric spatial representation, Behavioural Brain Research, 236, 2013, 175-179.

[37] A. Pasqualotto and T. Esenkaya, Sensory substitution: the spatial updating of auditory scenes "Mimics" the spatial updating of visual scenes, Frontiers in Behavioral Neuroscience, 10, 2016, 79 .

[38] B. Röder, F. Rösler, and H.J. Neville, Event-related potentials during auditory language processing in congenitally blind and sighted people, Neuropsychologia, 38(11), 2000, 1482-1502.

[39] B. Röder, F. Rösler, and H.J. Neville, Auditory memory in congenitally blind adults: a behavioral-electrophysiological investigation. Cognitive Brain Research, 11(2), 2001, 289-303.

[40] H. Siamian, M. Hassanzadeh, F. Nooshinfard, and N. Hariri, Information seeking behavior in blind people of Iran: A survey 
based on various experiences faced by them, Health Sciences, 3(4), 2016, 1-5.

[41] A.J. Kolarik, R. Raman, B.C. Moore, S. Cirstea, S. Gopalakrishnan, and S. Pardhan, Partial visual loss affects self-reports of hearing abilities measured using a modified version of the speech, spatial, and qualities of hearing questionnaire, Frontiers in Psychology, 8, 2017, 1-16.

[42] A.J. Kolarik, A.C. Scarfe, B.C.J. Moore, and S. Pardhan Blindness enhances auditory obstacle circumvention: Assessing echolocation, sensory substitution, and visual-based navigation, PLoS One, 12(4), 2017, e0175750.

[43] A.C. Livingstone, G.J. Christie, R.D. Wright, and J.J. Mcdonald, Signal enhancement, not active suppression, follows the contingent capture of visual attention, Journal of Experimental Psychology: Human Perception and Performance, 43(2), 2017, 219-224.

[44] P. Voss, Auditory spatial perception without vision, Frontiers in Psychology, 7, 2016, 1-7.

[45] C. Lane, S. Kanjlia, H. Richardson, A. Fulton, A. Omaki, and M. Bedny, Reduced left lateralization of language in congenitally blind individuals, Journal of Cognitive Neuroscience, 29(1), 2016, 1-14.

[46] K.J. Price, M. Lin, J. Feng, R. Goldman, A. Sears, and J. Jacko, Nomadic speech-based text entry: A decision model strategy for improved speech to text processing, International Journal of Human-Computer Interaction, 25(7), 2009, 692-706.

[47] R.J. Lutz, Prototyping and evaluation of landcons, $A C M$ SIGACCESS Accessibility \& Computing, 86, 2006, 8-11.

[48] J. Kostiainen, C. Erkut, and F.B. Piella, Design of an audio-based mobile journey planner application, International Academic Mindtrek Conference: Envisioning Future Media Environments, 2011, 107-113.

[49] M. Jeon and B.N. Walker, Spindex (speech index) improves auditory menu acceptance and navigation performance, $A C M$ Transactions on Accessible Computing, 3(3), 2011, 1-26.

[50] B.K. Davison, Menu navigation with in-vehicle technologies: Auditory menu cues improve dual task performance, preference, and workload, International Journal of HumanComputer Interaction, 31(1), 2015, 1-16.

[51] Á. Csapó and G. Wersényi, Overview of auditory representations in human-machine interfaces, ACM Computing Surveys, 46(2), 2013, 1-23.

[52] I. Hussain, L. Chen, H.T. Mirza, G. Chen, and S.-U. Hassan, Right mix of speech and non-speech: hybrid auditory feedback in mobility assistance of the visually impaired, Universal Access in the Information Society, 14(4), 2015, 527-536.

[53] I. Hussain, L. Chen, H.T. Mirza, L. Wang, G. Chen, and I. Memon, Chinese-based spearcons: improving pedestrian navigation performance in eyes-free environment, International Journal of Human-Computer Interaction, 32(6), 2016, 460-469.

[54] I. Hussain, L. Chen, H.T. Mirza, K. Xing, and G. Chen, A comparative study of sonification methods to represent distance and forward-direction in pedestrian navigation, International Journal of Human-Computer Interaction, 30(9), 2014, 740-751.

[55] E.L. Horton, R. Renganathan, B.N. Toth, et al., A review of principles in design and usability testing of tactile technology for individuals with visual impairments, Assistive Technology, 29(1), 2017, 28-36.

[56] Y. Zeng, D. Li, and G. Zhai, Indoor localization system for individuals with visual impairment, in J. Zhou (ed.), International forum of digital $T V \&$ wireless multimedia communication (Shanghai: Springer, 2018), 478-491.

[57] M.A. Heller, M. Mccarthy, and A. Clark, pattern perception and pictures for the blind, Psicológica, 26(1), 2005 161-171.

[58] V. Occelli, S. Lacey, C. Stephens, T. John, and K. Sathian, Haptic object recognition is view-independent in early blind but not sighted people, Perception, 45(3), 2016, 337-45.

[59] D. Picard, J.-M. Albaret, and A. Mazella, Haptic identification of raised-line drawings by children, adolescents and young adults: An age-related skill, Haptics-e, 5(2), 2013, 24-8.
[60] C. Carpio, M. Amérigo, and M. Durán, Study of an inclusive intervention programme in pictorial perception with blind and sighted students, European Journal of Special Needs Education, 32(4), 2017, 525-542.

[61] I. Puspitawati, A. Jebrane, and A. Vinter, Local and global processing in blind and sighted children in a naming and drawing task, Child Development, 85(3), 2014, 1077-1090.

[62] B. Andò, C. Lombardo, and V. Marletta, Smart homecare technologies for the visually impaired: Recent advances, Smart Homecare Technology and TeleHealth, 3, 2015, 9-16.

[63] P. Bach-y-Rita, C.C. Collins, F.A. Saunders, B. White, and L. Scadden, Vision substitution by tactile image projection, Nature, 221(5184), 1969, 963-964.

[64] D.-R. Chebat, F.C. Schneider, R. Kupers, and M. Ptito, Navigation with a sensory substitution device in congenitally blind individuals, Neuroreport, 22(7), 2011, 342-347.

[65] P.B. Meijer, An experimental system for auditory image representations, IEEE Transactions on Biomedical Engineering, 39(2), 1992, 112-121.

[66] M.J. Proulx, P. Stoerig, E. Ludowig, and I. Knoll, Seeing 'where' through the ears: effects of learning-by-doing and long-term sensory deprivation on localization based on imageto-sound substitution, PLoS One, 3(3), 2008, e1840.

[67] D.J. Brown and M.J. Proulx, Audio-vision substitution for blind individuals: Addressing human information processing capacity limitations, IEEE Journal of Selected Topics in Signal Processing, 10(5), 2016, 924-931.

[68] A. Amedi, W.M. Stern, J.A. Camprodon, et al., Shape conveyed by visual-to-auditory sensory substitution activates the lateral occipital complex, Nature Neuroscience, 10(6) 2007, 687.

[69] L.F. Cuturi, E. Aggius-Vella, C. Campus, A. Parmiggiani, and M. Gori, From science to technology: Orientation and mobility in blind children and adults, Neuroscience $\&$ Biobehavioral Reviews, 71(Supplement C), 2016, 240-251.

[70] D. Bolgiano and E. Meeks, A laser cane for the blind, IEEE Journal of Quantum Electronics, 3(6), 2003, 268-268.

[71] P. Vera, D. Zenteno, and J. Salas, A smartphone-based virtual white cane, Pattern Analysis and Applications, 17(3), 2014, 623-632

[72] Q.K. Dang, Y. Chee, D.D. Pham, and Y.S. Suh, A virtual blind cane using a line laser-based vision system and an inertial measurement unit, Sensors, 16(1), 2016, 1-18.

[73] A. Majeed and S. Baadel, Facial recognition cane for the visually impaired (Springer International Publishing, 2017) 394-405.

[74] C. Ye, S. Hong, X. Qian, and W. Wu, Co-robotic cane: A new robotic navigation aid for the visually impaired, IEEE Systems, Man, and Cybernetics Magazine, 2(2), 2016, 33-42.

[75] K. Kumar, B. Champaty, K. Uvanesh, and R. Chachan, Development of an ultrasonic cane as a navigation aid for the blind people, International Conference on Control, Instrumentation, Communication and Computational Technologies 2014, 475-479.

[76] S. Gupta, I. Sharma, A. Tiwari, and G. Chitranshi, Advanced guide cane for the visually impaired people, International Conference on Next Generation Computing Technologies, 2016, 452-455.

[77] H.R. Shah, D.B. Uchil, S.S. Rane, P. Shete, and B.E. Student, Smart stick for blind using arduino, ultrasonic sensor and android, International Journal of Engineering Science, 7(4), 2017, 10929-10933.

[78] S. Sharma, M. Gupta, A. Kumar, M. Tripathi, and M.S. Gaur, Multiple distance sensors based smart stick for visually impaired people, Computing and Communication Workshop and Conference, 2017, 1-5.

[79] Bay Advanced Technologies Ltd., 2016, Available from: http://www.ksonar.com/.

[80] G. Buchs, N. Simon, S. Maidenbaum, and A. Amedi, Waistup protection for blind individuals using the EyeCane as a primary and secondary mobility aid, Restorative Neurology and Neuroscience, 35(2), 2017, 225-235. 
[81] A. Krishnan, G. Deepakraj, N. Nishanth, and K.M. Anandkumar, Autonomous walking stick for the blind using echolocation and image processing, International Conference on Contemporary Computing and Informatics, 2017, 13-16.

[82] Y. Niitsu, T. Taniguchi, and K. Kawashima, Detection and notification of dangerous obstacles and places for visually impaired persons using a smart cane, Seventh International Conference on Mobile Computing and Ubiquitous Networking, 2014, 68-69.

[83] A.C. Scherlen, J.C. Dumas, B. Guedj, and A. Vignot, "RecognizeCane": The new concept of a cane which recognizes the most common objects and safety clues, International Conference of IEEE Engineering in Medicine and Biology Society, 2007, 6356-6359.

[84] L. Kim, S. Park, S. Lee, and S. Ha, An electronic traveler aid for the blind using multiple range sensors, IEICE Electronics Express, 6(11), 2009, 794-799.

[85] I. Shim and J. Yoon, A robotic cane based on interactive technology, IECON, 2002, 2249-2254.

[86] M.Y. Fan, J.T. Bao, and H.R. Tang, A guide cane system for assisting the blind in travelling in outdoor environments, Applied Mechanics \& Materials, 631-632, 2014, 568-571.

[87] H. Takizawa, S. Yamaguchi, M. Aoyagi, N. Ezaki, and S. Mizuno, Kinect cane: An assistive system for the visually impaired based on the concept of object recognition aid, Personal and Ubiquitous Computing, 19(5-6), 2015, 955-965.

[88] A.M. Kassim, T. Yasuno, H. Suzuki, H.I. Jaafar, and M.S.M. Aras, Indoor navigation system based on passive RFID transponder with digital compass for visually impaired people, International Journal of Advanced Computer Science 83 Applications, 7(2), 2016, 604-611.

[89] S. Pisa, E. Pittella, and E. Piuzzi, Serial patch array antenna for an FMCW radar housed in a white cane, International Journal of Antennas and Propagation, 2016, 2016, 1-10.

[90] S.A.D. Silva and D. Dias, A sensor platform for the visually impaired to walk straight avoiding obstacles, International Conference on Sensing Technology, 2016.

[91] R. Satpute, M. Mansuri, D. Kulkarni, A. Sawant, Smart cane for visually impaired person by using arduino, Imperial Journal of Interdisciplinary Research, 3(5), 2016, $1104-1108$.

[92] J.-R. Rizzo, K. Conti, T. Thomas, T.E. Hudson, R. Wall Emerson, and D.S. Kim, A new primary mobility tool for the visually impaired: A white cane-adaptive mobility device hybrid, Assistive Technology, 2017, 1-7

[93] T. Sugimoto, S. Nakashima, and Y. Kitazono, Development of guiding walking support device for visually impaired people with the GPS, in R. Lee (ed.), Applied computing and information technology (Cham: Springer International Publishing, 2017), 77-89.

[94] S. Wankhade, M. Bichukale, S. Desai, S. Kamthe, and A. Borate, Smart stick for blind people with live video feed, International Research Journal of Engineering and Technology, 4(3), 2017, 1774-1778.

[95] D. De Alwis and Y.C. Samarawickrama, Low cost ultrasonic based wide detection range smart walking stick for visually impaired, International Journal of multidisciplinary Studies, 3(2), 2016, 123-130.

[96] M. Pinto, R.D. Stanley, S. Malagi, and M.K. Ajithanjaya Kumar, Smart cane for the visually impaired, American Journal of Intelligent Systems, 7(3), 2017, 73-76.

[97] G.Y. Jeong and K.H. Yu, Multi-section sensing and vibrotactile perception for walking guide of visually impaired person, Sensors, 16(7), 2016, 1-19.

[98] M.S. Sadi, S. Mahmud, Md.M. Kamal, and A.I. Bayazid, Automated walk-in assistant for the blinds, International Conference on Electrical Engineering and Information 83 Communication Technology, 2014.

[99] A.M. Kassim, T. Yasuno, H. Suzuki, et al., Conceptual design and implementation of electronic spectacle based obstacle detection for visually impaired persons, Journal of Advanced Mechanical Design Systems \& Manufacturing, 10(7), 2016, $1-12$

[100] C. Yi and Y. Tian, Assistive text reading from natural scene for blind persons, in G. Hua and X.-S. Hua (eds.), Mobile cloud visual media computing: From interaction to service (Cham: Springer International Publishing, 2015), 219-241.

[101] E.A. Hassan and T.B. Tang. Smart glasses for the visually impaired people, International Conference on Computers Helping People with Special Needs, 2016, 579-582.

[102] L. Everding, L. Walger, V.S. Ghaderi, and J. Conradt, A mobility device for the blind with improved vertical resolution using dynamic vision sensors, IEEE International Conference on E-Health Networking, Applications and Services, 2016, $1-5$.

[103] S. Wang, X. Yang, and Y. Tian, Detecting signage and doors for blind navigation and wayfinding, Network Modeling Analysis in Health Informatics and Bioinformatics, 2(2), 2013, 81-93.

[104] S. Pundlik, H. Yi, R. Liu, E. Peli, and G. Luo, Magnifying smartphone screen using Google Glass for low-vision users, IEEE Transactions on Neural Systems and Rehabilitation Engineering, 25(1), 2017, 52-61.

[105] L.B. Neto, F. Grijalva, V.R.M.L. Maike, et al., A Kinect-based wearable face recognition system to aid visually impaired users, IEEE Transactions on Human-Machine Systems, 47(1), 2017, 52-64.

[106] C. Stoll, R. Palluel-Germain, V. Fristot, D. Pellerin, D. Alleysson, and C. Graff, Navigating from a depth image converted into sound, Applied Bionics and Biomechanics, 2015, 2015, 1-9.

[107] S.L. Hicks, I. Wilson, J.J. van Rheede, R.E. MacLaren, S.M. Downes, and C. Kennard, Improved mobility with depthbased residual vision glasses, Investigative Ophthalmology 8 Visual Science, 55(13), 2014, 2153-2153.

[108] Y. Wu, C.P. Chen, L. Zhou, Y. Li, B. Yu, and H. Jin, Design of see-through near-eye display for presbyopia, Optics Express, 25(8), 2017, 8937-8949.

[109] A. Berger, A. Vokalova, F. Maly, and P. Poulova, Google Glass used as assistive technology its utilization for blind and visually impaired people, International Conference on Mobile Web and Information Systems. 2017. p. 70-82.

[110] R. McNaney, J. Vines, D. Roggen, et al., Exploring the acceptability of Google Glass as an everyday assistive device for people with Parkinson's, Proceedings of the 32nd Annual ACM Conference on Human Factors in Computing Systems, 2014, 2551-2554.

[111] J.-H. Jung, D. Aloni, Y. Yitzhaky, and E. Peli, Active confocal imaging for visual prostheses, Vision Research, 111 (Part B), 2015, 182-196.

[112] F. Lan, G. Zhai, and W. Lin, Lightweight smart glass system with audio aid for visually impaired people, TENCON 2015 2015 IEEE Region 10 Conference, 2016.

[113] Google Glass Inc. 2012, available from: https://x.company/ glass/

[114] eSight 3 Co. 2017, available from: https://www.esighteyewear. $\mathrm{com} /$

[115] OrCam Technologies Ltd. 2015, available from: https://www. orcam.com/

[116] Enchroma Inc. 2013, available from: http://enchroma.com/ shop/

[117] Hangzhou KR-VISION Technology Co., Ltd. Intoer. 2017, available from: http://www.krvision.cn/

[118] Wicab, Inc. BrainPort ${ }^{\circledR}$ V100. 2015, available from: https://www.wicab.com/

[119] S. Wang, H. Pan, C. Zhang, and Y. Tian, RGB-D image-based detection of stairs, pedestrian crosswalks and traffic signs, Journal of Visual Communication and Image Representation, 25(2), 2014, 263-272.

[120] T.T. Satue and M.B.A. Miah, An obstacle detection in order to reduce navigation difficulties for visually impaired people, International Journal of Computer Applications, 161(6), 2017, 39-41.

[121] V.C. Sekhar, S. Bora, M. Das, P.K. Manchi, S. Josephine, and R. Paily, Design and implementation of blind assistance system using real time stereo vision algorithms, International Conference on VLSI Design and 2016 International Conference on Embedded Systems, 2016, 421-426.

[122] A.S. Rao, J. Gubbi, M. Palaniswami, and E. Wong, A vision-based system to detect potholes and uneven surfaces 
for assisting blind people, IEEE International Conference on Communications, 2016, 1-6.

[123] P. Gharani and H.A. Karimi, Context-aware obstacle detection for navigation by visually impaired, Image and Vision Computing, 64 (Supplement C), 2017, 103-115.

[124] S. Shoval, I. Ulrich, and J. Borenstein, NavBelt and the Guide-Cane [obstacle-avoidance systems for the blind and visually impaired], Robotics \& Automation Magazine IEEE, 10(1), 2003, 9-20.

[125] K.P. Reshma, Ultrasonic spectacles design and waist-belt for blind navigation, International Journal of Engineering Research and Innovative Technology, 1(1), 2014, 19-22.

[126] A. Wattal, A. Ojha, and M. Kumar, Obstacle detection for visually impaired using raspberry $\mathrm{Pi}$ and ultrasonic sensors, National Conference on Product Design, 2016, 1-5.

[127] B. Mocanu, R. Tapu, and T. Zaharia, When ultrasonic sensors and computer vision join forces for efficient obstacle detection and recognition, Sensors, 16(11), 2016, 1-23.

[128] A.C. Pattanshetti, S.I.A. Bhat, and H.G. Choudhari, Advanced bat hat for the visually impaired, Imperial Journal of Interdisciplinary Research, 2(6), 2016, 879-884.

[129] S. Bhatlawande, M. Mahadevappa, and J. Mukhopadhyay, Way-finding electronic bracelet for visually impaired people, Point-Of-Care Healthcare Technologies, 2013, 260-263.

[130] R. Rangarajan and M.B. Benslija, Voice recognition robotic dog guides for visually impaired people, IOSR Journal of Electronics and Communication Engineering, 9(2), 2014, 133-139.

[131] B.S. Lin, C.C. Lee, and P.Y. Chiang, Simple smartphonebased guiding system for visually impaired people, Sensors, $17(6), 2017,1-22$.

[132] J.-H. Lee, D. Kim, and B.-S. Shin, A wearable guidance system incorporating multiple sensors for visually impaired persons, in J.J. Park, Y. Pan, C.-S. Kim, and Y. Yang (eds.), Future Information Technology: FutureTech 2014 (Berlin, Heidelberg: Springer Berlin Heidelberg, 2014), 541-548.

[133] C.-G. Kim and B.-S. Song, Proposal of a simultaneous ultrasound emission for efficient obstacle searching in autonomous wheelchairs, Biomedical Engineering Letters, 3(1), 2013, 47-50.

[134] W. Fang, G. Zhai, and X. Yang, A flash light system for individuals with visual impairment based on TPVM, Cloud Computing and Big Data (CCBD), 2016 7th International Conference on, 2016, 362-366.

[135] S. Bhatlawande, A. Sunkari, M. Mahadevappa, et al., Electronic bracelet and vision-enabled waist-belt for mobility of visually impaired people, Assistive Technology the Official Journal of RESNA, 26(4), 2014, 186-195.

[136] S. Sivagami, V. Kushmitha, D. Dinesh, T. Amala, and M. Anu Priyam, The Navaid - A navigation system for visually challenged obstacle detection using ultrasonic sensors, International Journal of Advance Research, Ideas and Innovations in Technology, 3(2), 2017, 1207-1211.

[137] I.R. Altaha and J.M. Rhee. Blindness support using a 3D sound system based on a proximity sensor, IEEE International Conference on Consumer Electronics, 2016, 51-54.

[138] T. Froneman, D. van den Heever, and K. Dellimore, Development of a wearable support system to aid the visually impaired in independent mobilization and navigation, The 39th Annual International Conference of the IEEE on Engineering in Medicine and Biology Society, 2017, 783-786.

[139] M.L. Mekhalfi, F. Melgani, Y. Bazi, and N. Alajlan, Fast indoor scene description for blind people with multiresolution random projections, Journal of Visual Communication and Image Representation, 44(Supplement C), 2017, 95-105.

[140] T.F. Wu, P.S. Tsai, N.T. Hu, and J.Y. Chen, Intelligent wheeled mobile robots for blind navigation application, Engineering Computations, 34(2), 2017, 214-238.

[141] A. Spiers and A. Dollar, Design and evaluation of shapechanging haptic interfaces for pedestrian navigation assistance, IEEE Transactions on Haptics, 10(1), 2016, 17-28.

[142] J.-R. Rizzo, Y. Pan, T. Hudson, E.K. Wong, and Y. Fang, Sensor fusion for ecologically valid obstacle identification: Building a comprehensive assistive technology platform for the visually impaired, 7th International Conference on Modeling, Simulation, and Applied Optimization, 2017, 1-5.
[143] M. Bedny, Evidence from blindness for a cognitively pluripotent cortex, Trends in Cognitive Sciences, 21(9), 2017, 637648.

[144] K. Hötting and B. Röder, Auditory and auditory-tactile processing in congenitally blind humans, Hearing Research, 258(1), 2009, 165-174.

[145] J. Ni, Y. Chen., K. Wang, and S.X. Yang, An improved vision-based SLAM approach inspired from animal spatial cognition, International Journal of Robotics and Automation, 2019. DOI: 10.2316/J.2019.206-0116.

\section{Biographies}

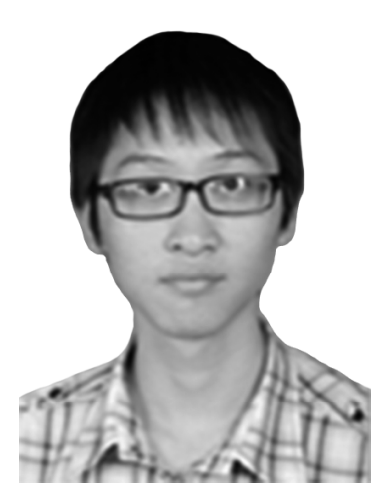

Menghan $H u$ received the Ph.D. degree (Hons.) in biomedical engineering from the University of Shanghai for Science and Technology in 2016. From 2016 to 2018, he was a Post-Doctoral Researcher with Shanghai Jiao Tong University. He is currently an Associate Professor with the Shanghai Key Laboratory of Multidimensional Information Processing, East China Normal University.

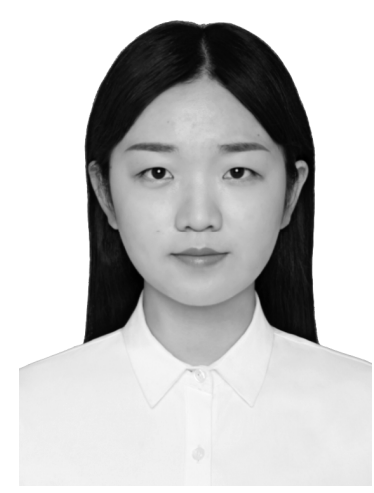

Yuzhen Chen received the B.E. degree in communication engineering from East China Normal University, Shanghai, China, in 2019. She is currently preparing for the postgraduate of East China Normal University.

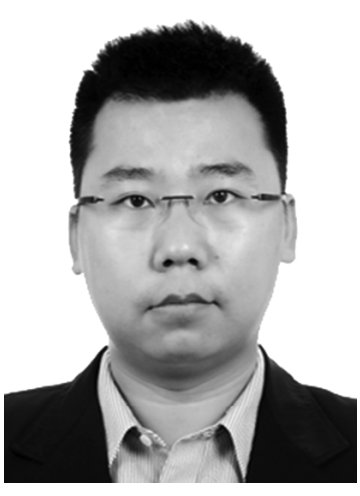

Guangtao Zhai received the B.E. and M.E. degrees from Shandong University, Shandong, China, in 2001 and 2004, respectively, and the Ph.D. degree from Shanghai Jiao Tong University, Shanghai, China, in 2009. From 2008 to 2009, he was a Visiting Student with the Department of Electrical and Computer Engineering, McMaster University, Hamilton, ON, Canada, where he was a PostDoctoral Fellow from 2010 to 2012. From 2012 to 2013, he was a Humboldt Research Fellow with the Institute of Multimedia Communication and Signal Processing, Friedrich Alexander University of Erlangen-Nuremberg, Germany. He is currently a Research Professor with the Institute of Image Communication and Information Processing, Shanghai Jiao Tong University. His research interests include multimedia signal processing and perceptual signal processing. He received the Award of National Excellent Ph.D. Thesis from the Ministry of Education of China in 2012. 


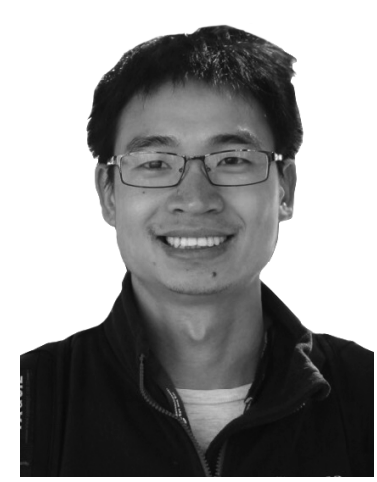

Zhongpai Gao received the B.Sc. degree in electronic and information engineering from the Huazhong University of Science and Technology, Wuhan, China, in 2013. He is currently pursuing the Ph.D. degree in electrical engineering with Shanghai Jiao Tong University, Shanghai, China. He was a Visiting Ph.D. Student with the Schepens Eye Research Institute, Harvard Medical School, Boston, USA, from 2016 to 2018. His research interests include multimedia signal processing, stereoscopic $3 \mathrm{D}$, visually induced motion sickness and psychovisual modulation display technology.

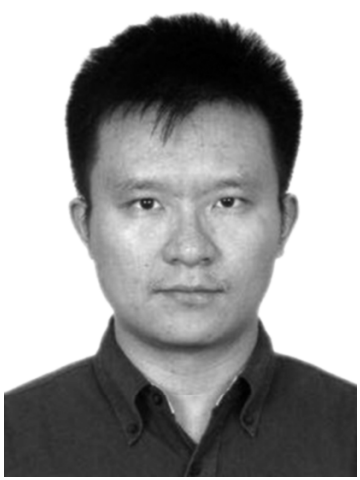

Lei Fan received the B.Sc. degree in electronic and information engineering from the Shandong University, Jinan, China, in 2003. He is currently the lab manager of Multimedia Lab in Shanghai Jiao Tong University, Shanghai, China. 